\title{
SCOPING CALCULATIONS FOR GROUNDWATER TRANSPORT OF TRITIUM FROM THE GNOME SITE, NEW MEXICO
}

\author{
by
}

Karl Pohlmann and Roko Andricevic
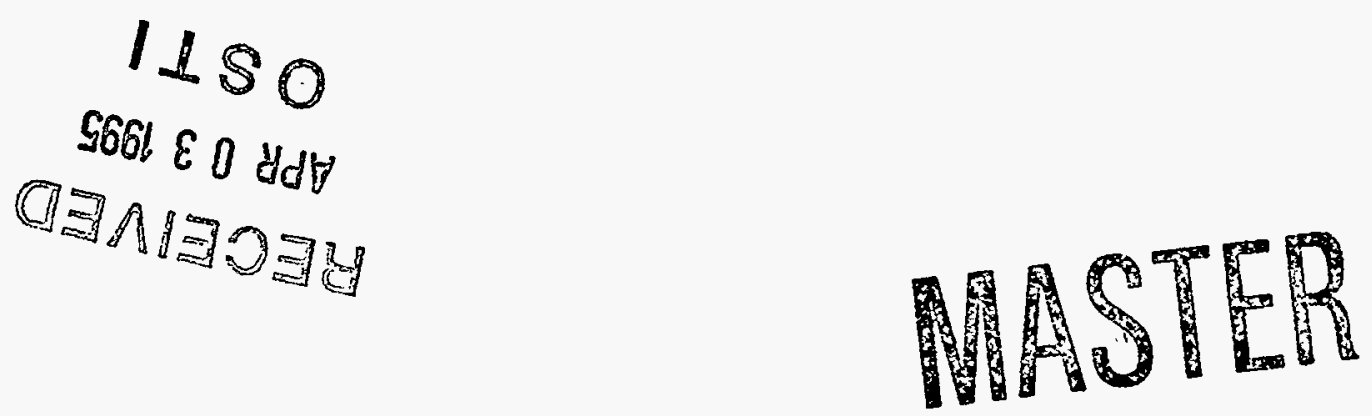

\section{AUGUST 1994}

DISTRIBUTION OE THIS DOCUMENT IS UNLIMITED

Publication \#45126

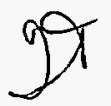


This report was prepared as an account of work sponsored by the United States Government. Neither the United States nor the United States Department of Energy, nor any of their employees, makes any warranty, express or implied, or assumes any legal liability or responsibility for the accuracy, completeness or usefulness of any information, apparatus, product or process disclosed, or represents that its use would not infringe privately owned rights. Reference herein to any specific commercial product, process, or service by trade name, mark, manufacturer, or otherwise, does not necessarily constitute or imply its endorsement, recommendation, or favoring by the United States Government or any agency thereof. The views and opinions of authors expressed herein do not necessarily state or reflect those of the United States Government or any agency thereof.

This report has been reproduced directly from the best available copy.

Available to DOE and DOE contractors from the Office of Scientific and Technical Information, P.O. Box 62, Oak Ridge, TN 37831; prices available from (615) 576-8401.

Available to the public from the National Technical Information Service, U.S. Department of Commerce, 5285 Port Royal Rd., Springfield, VA 22161. 


\section{DISCLAIMER}

Portions of this document may be illegible in electronic image products. Images are produced from the best available original document. 


\title{
SCOPING CALCULATIONS FOR GROUNDWATER TRANSPORT OF TRITIUM FROM THE GNOME SITE, NEW MEXICO
}

\author{
by \\ Karl Pohlmann and Roko Andricevic \\ Water Resources Center \\ Desert Research Institute \\ Publication No. 45126 \\ prepared for \\ Nevada Operations Office \\ U.S. Department of Energy \\ Las Vegas, Nevada
}

University and Community College System of Nevada

August 1994

The work upon which this report is based was supported by the U.S. Department of Energy under Contract \#DE-AC08-90NV10845. 


\begin{abstract}
Analytic solutions are employed to investigate potential groundwater transport of tritium from a radioactive tracer site near the Project Gnome site in southeastern New Mexico. The tracer test was conducted in 1963 and introduced significant quantities of radionuclides to the transmissive and laterally continuous Culebra dolomite. Groundwater in the Culebra near Gnome travels toward a regional discharge point at the Pecos River, a distance of about 10 to $15 \mathrm{~km}$, depending on flow path. Groundwater transport of radionuclides from the Gnome site is therefore of interest due to the proximity of the accessible environment and the 31-year time period during which migration is likely to have occurred. The analytical stochastic solutions used incorporate the heterogeneity observed in the Culebra by treating transmissivity as a spatially correlated random field.

The results indicate that significant spreading of tritium will occur in the Culebra dolomite as a result of the combination of relatively high transmissivity, high spatial variability, and high spatial correlation of transmissivity. Longitudinal spreading may cause a very small fraction of tritium mass to arrive at the Pecos River within the 31 years since the tracer test. However, dilution and transverse dispersion will act to distribute this mass over a very large volume, thereby reducing groundwater concentrations. Despite the high degree of spreading, the calculations indicate that most of the tritium remains near the source. At present, the center of mass is estimated to have moved approximately $260 \mathrm{~m}$ downgradient of the test location and about 95 percent of the mass is estimated to have remained within about $1 \mathrm{~km}$ downgradient.
\end{abstract}




\section{CONTENTS}

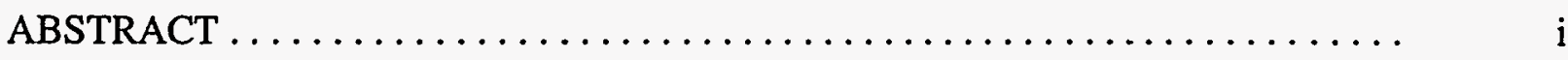

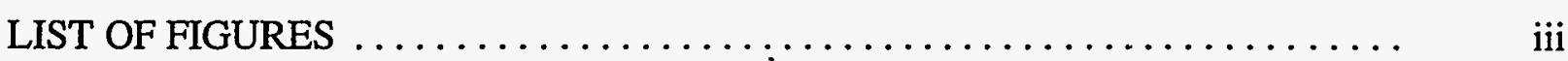

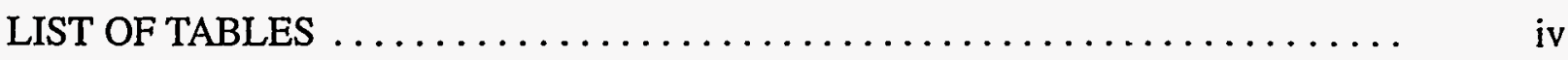

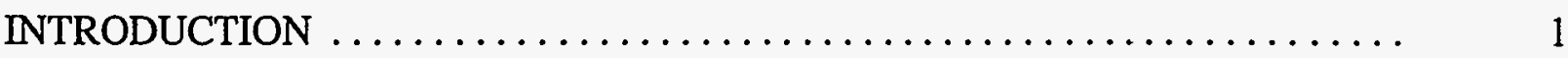

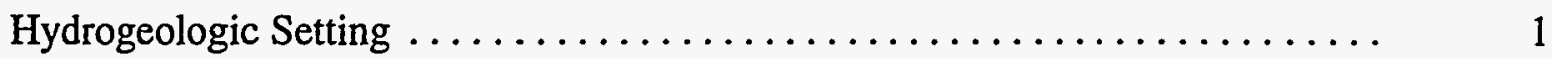

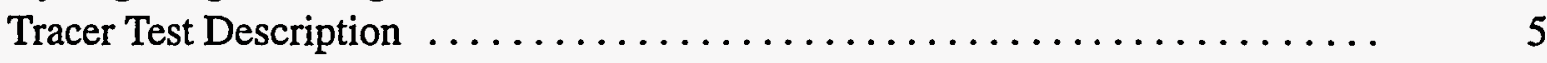

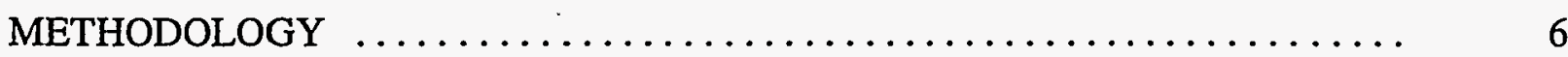

APPLICATION AND RESULTS $\ldots \ldots \ldots \ldots \ldots \ldots \ldots \ldots \ldots \ldots \ldots \ldots \ldots \ldots . \ldots \ldots$

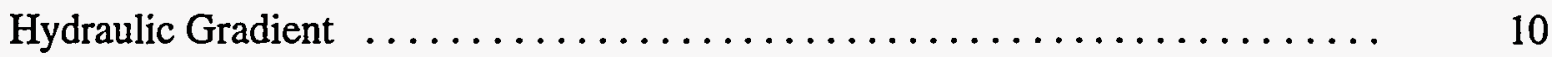

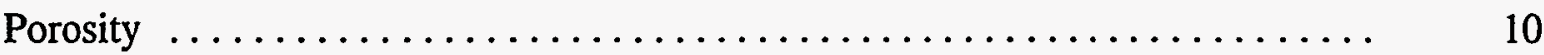

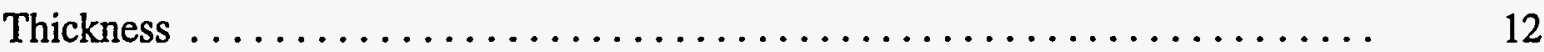

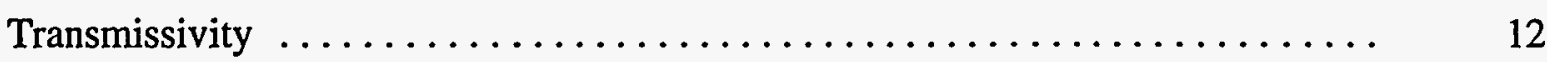

Spatial Correlation Scale .............................. 14

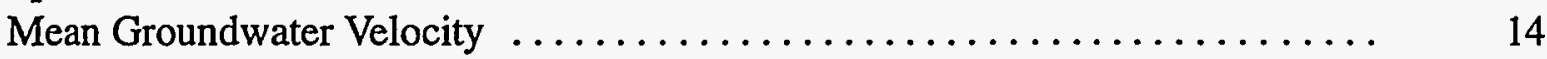

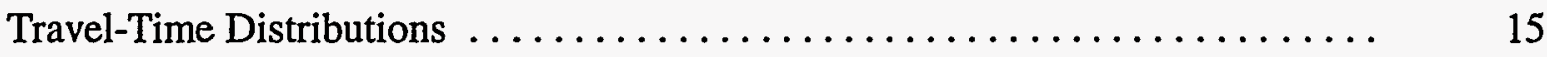

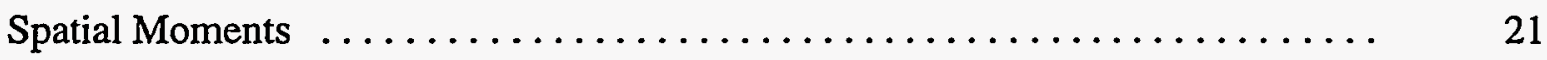

CONCLUSIONS AND RECOMMENDATIONS ................... 26

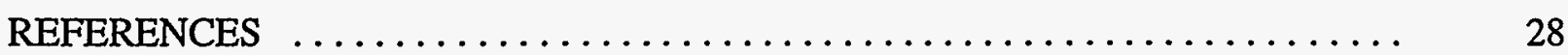

APPENDIX A: DESCRIPTION OF TRAVEL-TIME AND

SPATIAL-MOMENTS METHODS $\ldots \ldots \ldots \ldots \ldots \ldots \ldots \ldots . \quad 30$

APPENDIX B: WELL DATA FOR THE VICINITY OF GNOME $\ldots \ldots \ldots \ldots \ldots .35$

APPENDIX C: VARIOGRAMS OF TRANSMISSIVITY IN THE

CULEBRA DOLOMITE ........................ 37 


\section{LIST OF FIGURES}

1. Cross section through Project Gnome site showing relation of nuclear cavity, drift, and shaft to local stratigraphy $\ldots \ldots \ldots \ldots \ldots \ldots \ldots \ldots \ldots \ldots \ldots \ldots \ldots$

2. Relation of Gnome location to dissolution of halite in the upper

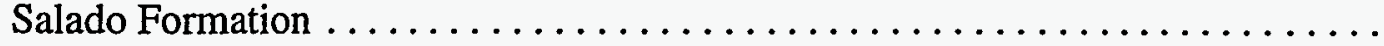

3. Potentiometric surface in the vicinity of Gnome $\ldots \ldots \ldots \ldots \ldots \ldots \ldots \ldots . \ldots \ldots$

4. Locations of wells in the vicinity of Gnome used for analysis of the

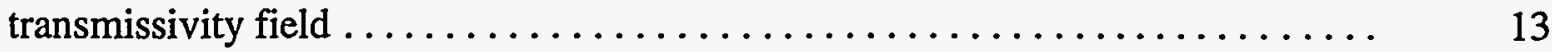

5. Distribution of uncertainty in mean advective groundwater velocity, $U$. ..... 15

6. Travel-time distribution at the Pecos River with and without radioactive

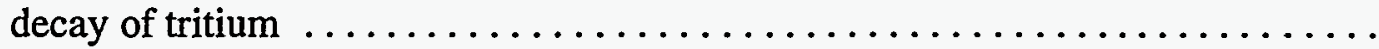

7. Sensitivity of the travel-time distribution at the Pecos River to

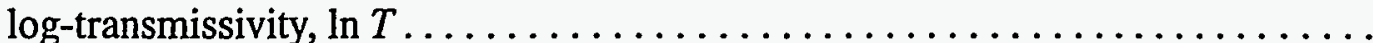

8. Sensitivity of the travel-time distribution at the Pecos River to correlated

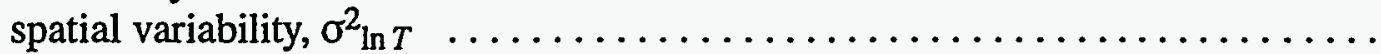

9. Sensitivity of the travel-time distribution at the Pecos River to spatial

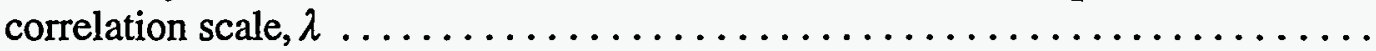

10. Sensitivity of the travel-time distribution at the Pecos River to uncertainty in

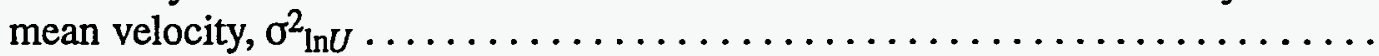

11. Spatial moments of tritium displacement at 11,31 , and 100 years after the tracer test

12. Relation of tritium displacement to geography in the vicinity of Gnome .......

13. Tritium displacement verses time represented by the location of the leading edge, width, and center of mass . . . . . . . . . . . . . . . . . . . . . .

14. Sensitivity of tritium displacement to transmissivity, $T$, at $\mathrm{t}=31$ years

15. Sensitivity of tritium displacement to spatial correlation scale,

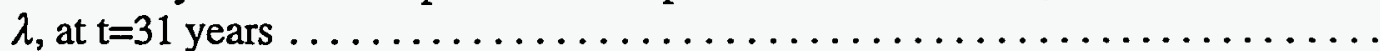

16. Sensitivity of tritium displacement to correlated spatial variability, $\sigma^{2} \ln T$, at $t=31$ years

C1.Experimental and theoretical variograms for Dataset 1

C2. Experimental and theoretical variograms for Dataset 2

C3.Experimental and theoretical variograms for Dataset 3 


\section{LIST OF TABLES}

1. Generalized Stratigraphic Section of Rocks Exposed in the Gnome Shaft ...... 3

2. Values of Input Parameters $\ldots \ldots \ldots \ldots \ldots \ldots \ldots \ldots \ldots \ldots \ldots \ldots \ldots \ldots \ldots \ldots$

3. Results of Variogram Analysis of Log-Transmissivity Data ............ 12 


\section{INTRODUCTION}

Radioactive tracer studies were conducted by the U.S. Geological Survey (USGS) at the Project Gnome site, approximately $48 \mathrm{~km}$ southeast of Carlsbad, New Mexico, as part of the U.S. Atomic Energy Commission's efforts to characterize groundwater transport of radionuclides in fractured rocks. All testing was conducted in February and March of 1963 in the Culebra Dolomite member of the Permian-age Rustler Formation. Approximately 20 Curies (Ci) of tritium $\left({ }^{3} \mathrm{H}\right), 10$ $\mathrm{Ci}$ of cesium-137 $\left({ }^{137} \mathrm{Cs}\right), 10 \mathrm{Ci}$ of strontium-90 $\left({ }^{90} \mathrm{Sr}\right)$, and $4 \mathrm{Ci}$ of iodine-131 $\left({ }^{131} \mathrm{I}\right)$ were injected in a discharging-recharging well couplet. There was no reported attempt to remove these tracers from the Culebra Dolomite subsequent to the completion of testing so the radionuclides have been subjected to transport by groundwater during the 31 years since the tests. The groundwater hydraulic gradient near the Gnome site is directed southwest toward a regional discharge point at the Pecos River, therefore, the potential for groundwater transport of radionuclides to the accessible environment is of interest.

The purpose of this study is to investigate potential groundwater transport of the radionuclide tritium from the Gnome tracer tests. The objectives are to evaluate the potential for tritium migration to points of potential human accessibility and to delineate the area within which tritium migration could most readily be characterized through future drilling and sampling programs. Both of these objectives are addressed through examination of the hydrogeologic factors important to

groundwater transport using scoping calculations of tritium travel time and displacement. A travel-time approach is utilized to provide first-order approximations of radionuclide arrival times at the Pecos River, the assumed point of human accessibility. An analytical solution for the first two moments of tritium displacement is used to approximate the outer limits of the spatial distribution of tritium in the near field. It is recognized that uncertainty in the values of input parameters will influence the travel times and migration distances; therefore, both methods incorporate heterogeneity in the flow field by treating transmissivity as a spatially correlated random field. Uncertainty in parameter estimation of other hydrogeologic properties is also included in the travel-time methodology.

\section{Hydrogeologic Setting}

Project Gnome was the first nuclear detonation designed for peaceful purposes and the first underground event in the Plowshare program to take place outside the Nevada Test Site. The Gnome site is located in the northern part of the Permian-age Delaware Basin. The Delaware Basin is bounded by the horseshoe-shaped Capitan Reef and contains up to 5,550 m of sedimentary rocks that were deposited in a Permian sea. The Project Gnome detonation occurred on 10 December 1961 with the shotpoint at a depth of $371 \mathrm{~m}$ in bedded halite of the Salado Formation (Cooper and Glanzman, 1971) (Figure 1). Underlying the shot point are $350 \mathrm{~m}$ of Salado evaporites and $490 \mathrm{~m}$ of Castille Formation evaporites, followed by basin-fill clastics and carbonates. Although the units 


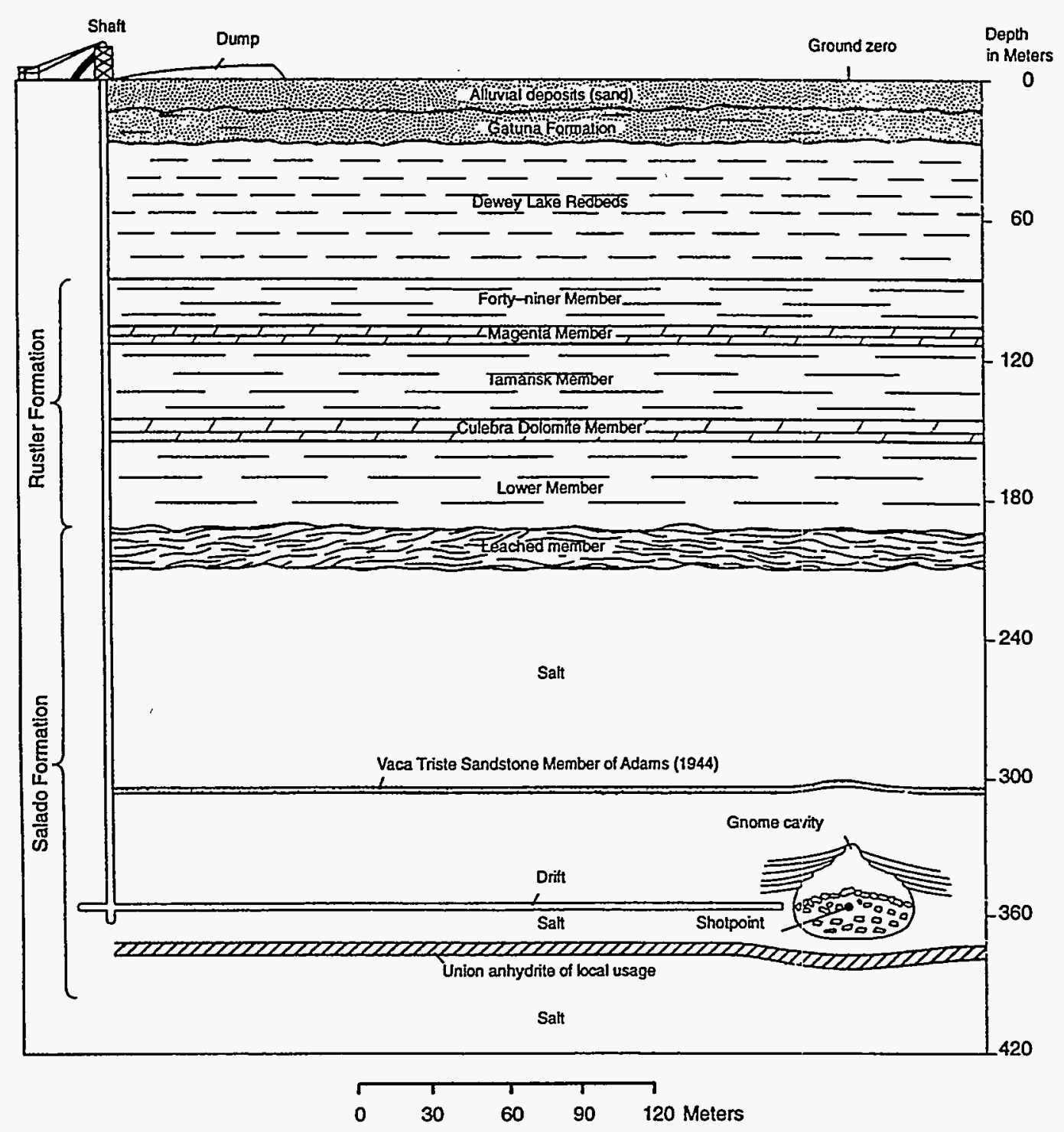

Figure 1. Cross section through Project Gnome site showing relation of nuclear cavity, drift, and shaft to local stratigraphy (after Gard, 1968). See Table 1 for stratigraphic descriptions.

below the shotpoint are important for their oil and gas resources, no potable aquifers are thought to occur in them in the vicinity of Gnome (Chapman and Hokett, 1991). Overlying the shotpoint are $170 \mathrm{~m}$ of Salado evaporites, the Rustler Formation, the Dewey Lake Redbeds, and Quaternary alluvial deposits. Evaporite dissolution within the Delaware Basin has impacted, and continues to impact, basin structure and stratigraphy through the removal of thick sections of evaporites. Subsequent differential collapse within the Rustler and lowering of the land surface have created surface depressions such as Nash Draw (Gard, 1968) which is to the north and west of the Gnome site (Figure 2). 
Table 1. Generalized Stratigraphic Section of Rocks Exposed in the Gnome Shaft (after Gard, 1968).

\begin{tabular}{|c|c|c|}
\hline Age & Unit & Lithology \\
\hline Recent & Alluvial bolson deposits & Unconsolidated sand \\
\hline Pleistocene(?) & Gatuna Formation & Friable sandstone and conglomerate \\
\hline \multirow[t]{3}{*}{ Late Permian } & Dewey Lake Redbeds & Thin-bedded siltstone \\
\hline & $\begin{array}{l}\text { Rustler Formation; } \\
\text { Forty-niner Member } \\
\text { Magenta Member } \\
\text { Tamarisk Member } \\
\text { Celebra Dolomite Member } \\
\text { Lower member }\end{array}$ & $\begin{array}{l}\text { Chiefly gypsum and anhydrite } \\
\text { Silty dolomite } \\
\text { Chiefly anhydrite and gypsum } \\
\text { Dolomite } \\
\text { Chiefly clay and silt, with some } \\
\text { gypsum and anhydrite }\end{array}$ \\
\hline & $\begin{array}{l}\text { Salado Formation; } \\
\text { Leached member } \\
\text { Unleached part }\end{array}$ & $\begin{array}{l}\text { Chiefly claystone and siltstone } \\
\text { Chiefly impure halite, with some } \\
\text { anhydrite, polyhalite, and siltstone. }\end{array}$ \\
\hline
\end{tabular}

The 110-m-thick Rustler Formation is predominantly composed of gypsum and anhydrite and generally has very low transmissivity. However, three units within the Rustler have been identified as aquifers: the Magenta dolomite, the Culebra dolomite, and a layer of dissolution residue at the base of the Rustler and the top of the Salado. Though both dolomite units are vuggy and fractured, the Magenta is above the regional potentiometric surface in the Gnome area (Cooper and Glanzman, 1971) and so is not considered important to groundwater transport in the vicinity of Gnome. On the other hand, the Culebra is very important to groundwater transport at the site because it is a widespread, laterally continuous confined aquifer in the Delaware Basin (Gard, 1968). The Culebra has been identified in hundreds of drillholes and has a uniform thickness of 9 to $12 \mathrm{~m}$ (Gard, 1968). Groundwater in the Culebra is believed to be recharged to the northwest and discharges into the alluvium adjacent to the Pecos River (Cooper and Glanzman, 1971). Though water quality in the Culebra is generally poor due to dissolved solids, it is the only source of water throughout much of the area and is used to supply local ranches. The dissolution residue contains brine so is not used as a water resource but, like the Culebra, discharges into the Pecos River. Units above the Rustler are not considered transmissive and/or laterally continuous enough to be important for groundwater transport (Cooper and Glanzman, 1971). 


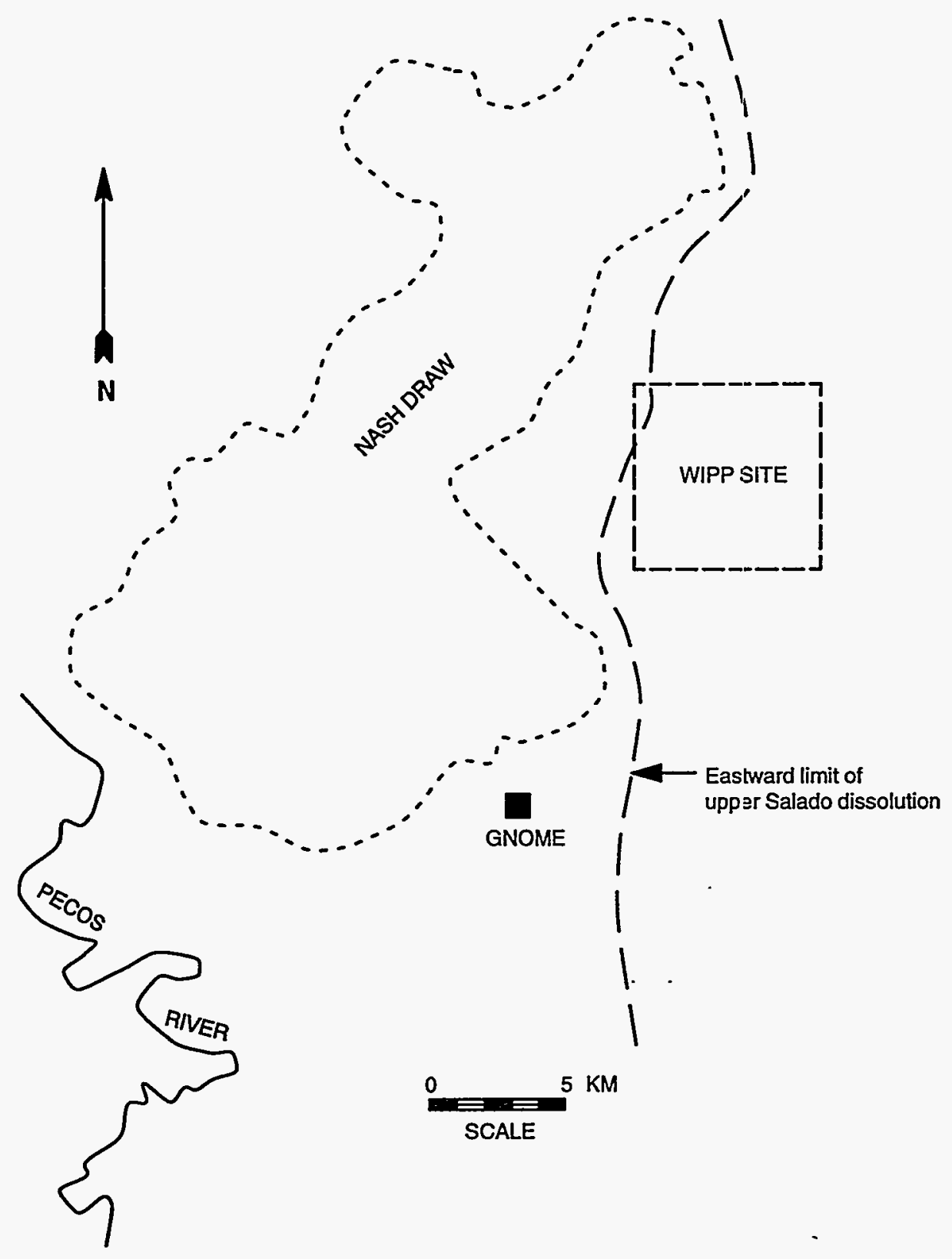

Figure 2. Relation of Gnome location to dissolution of halite in the upper Salado Formation. Nash Draw is the surficial expression of large-scale dissolution.

The degree of halite dissolution below the Culebra dolomite has been recognized as an important factor to groundwater flow and transport in the Culebra. Evidence from the Waste Isolation Pilot Plant (WIPP), which is approximately $9 \mathrm{~km}$ northeast of Gnome, suggests that when halite is removed by dissolution, stress is increased in the more competent overlying dolomite beds and they tend to fracture (Snyder, 1985; Lowenstein, 1987). The amount of halite dissolution below 
the Culebra dolomite has been observed to increase from east to west in the vicinity of Gnome. This trend is accompanied by a coincident increase in Culebra transmissivity across the area, presumably as a result of increased fracturing in the dolomite (Haug et al., 1987). As a result, Culebra transmissivity tends to increase downgradient (southwest) across the area, although much of the transmissivity data exist northeast of Gnome where the amount of halite dissolution is less and Culebra transmissivity is lower. This analysis focuses on the region in which dissolution of halite in the lower Rustler/upper Salado results in higher Culebra transmissivity.

\section{Tracer Test Description}

The tracer test conducted at the Gnome site was designed to obtain values of the dispersion coefficient and effective porosity to improve understanding and prediction of radionuclide transport in a fractured-rock aquifer similar to aquifers present at the Nevada Test Site. The two-well recirculating tracer test followed the method described by Grove and Beetem (1971) in which one well discharges from the aquifer and the second injects the water and tracer pumped from the first. When this system reaches steady state, the associated streamline arc lengths and travel times between the two wells can be calculated. The streamtubes formed by adjacent streamlines can be considered dispersion columns of known length and simulated breakthrough curves can be generated based on selected combinations of dispersion coefficient and effective porosity. Injecting a tracer into the steady-state flow field via the injection well, measuring tracer concentrations at the discharging well, and comparing the measured tracer breakthrough to the simulated breakthrough curves provide estimates of dispersion coefficient and effective porosity.

Two wells were drilled and constructed for the tracer test. Well USGS-8 is approximately 915 $\mathrm{m}$ west of Project Gnome ground zero and well USGS-4 is $38 \mathrm{~m}$ due west of USGS-8, although deviation from the vertical in USGS-4 causes the wells to be separated by approximately $55 \mathrm{~m}$ at depth. (Beetem and Angelo, 1964). Both wells are uncased throughout the 10.4-m thickness of the Culebra dolomite. A 15.24-cm-diameter steel pipe connected the injection well (USGS-8) to the discharge well (USGS-4). In the first phase of the test (9-15 February 1963), the discharge well was pumped at $168 \mathrm{~L} / \mathrm{min}$ until the discharge and recharge pressure responses indicated that flow conditions between the wells were approaching steady state. Slugs of the conservative tracers tritium and fluorescein (unknown quantities) were then added to the injection line to determine their dilution factors, and pumping continued for seven days while samples were collected from the discharge line. The pump was shut off and fluid pressures allowed to recover for two weeks prior to the initiation of the second phase of testing. The pump was started for the second phase on 21 February 1963 and steady-state conditions reestablished, followed by the addition of slugs of $18.5 \mathrm{Ci}$ of ${ }^{3} \mathrm{H}, 10 \mathrm{Ci}$ of ${ }^{137} \mathrm{Cs}, 10 \mathrm{Ci}$ of ${ }^{90} \mathrm{Sr}$, and $4 \mathrm{Ci}$ of ${ }^{131} \mathrm{I}$ to the injection line. Pumping continued for 16 days while samples were collected from the discharge line. The test was terminated on 9 March 1963 after the 
breakthrough curves were determined to be sufficiently developed for the analysis. Subsequent to the test, the discharge/injection pipe system was dismantled, the pump in USGS-4 was pulled, and the site surface cleaned up. There are no records of efforts to remediate the Culebra dolomite and the radioactive tracers therein. This study takes a conservative approach and assumes that the tracers were not removed after the test and, therefore, were free to be transported by groundwater. If some portion of the tracers was in fact removed, the magnitude of mass transported downgradient would be less that that estimated here.

\section{METHODOLOGY}

Subsurface porous media often display a large degree of variability in geologic properties which reflects the heterogeneity of most geologic formations. As a result, the hydrogeological parameters used to describe the medium, such as hydraulic conductivity and porosity, can also be highly variable. Successful predictions of the transport of solutes by groundwater have been found to depend most heavily on adequate characterization of hydraulic conductivity due to its high variability and strong influence on subsurface flow. The magnitude and variability of hydraulic conductivity controls the magnitude and variability of groundwater velocity which, in turn, causes the advection and dispersion of solute mass in groundwater.

Numerous studies of the spatial variability of hydraulic conductivity have concluded that it is generally log-normally distributed in natural hydrogeologic formations (Freeze and Cherry, 1979; Hoeksema and Kitinidis, 1985). In this report, transmissivity is used instead of hydraulic conductivity because most of the available hydraulic testing data correspond to tests that were conducted over the entire thickness of the Culebra Dolomite and because the thickness of the Culebra is relatively uniform over the study area. Thus, the natural logs of the measured transmissivity values can be described by a normal distribution with mean $\mu_{\ln T}$ and variance $\sigma^{2} \ln T$. The variance represents the degree of variability of $T$ in space and may range from near zero for homogeneous deposits, to five or higher for extremely variable porous media (Hoeksema and Kitinidis, 1985). Unless

specified otherwise, the term variability will be used in this report to refer to the spatial variability of transmissivity.

Because transmissivity is distributed in space, it usually has some degree of spatial correlation. The negative exponential function is often employed to describe the transmissivity correlation structure because it has been found to correspond to log hydraulic conductivity data and is easy to use (Hoeksema and Kitinidis, 1985). The spatial correlation is then a function of the distance between data points and the correlation length of transmissivity, $\lambda$, which represents the distance at which correlation between data points ceases. The higher the value of $\lambda$, the greater the spatial continuity of transmissivity. Unless specified otherwise, the term correlation will be used in this report to refer to the spatial correlation to transmissivity. 
If the log-normal distribution and the negative exponential covariance function are assumed, then a heterogeneous, isotropic transmissivity field can be statistically characterized by three parameters: $\mu_{\ln T}, \sigma^{2} \ln T$, and $\lambda$. Variability at a scale shorter than the sampling interval, as well as measurement uncertainty, is termed the nugget effect and is part of the total variability described by $\sigma^{2} \ln T$.

The methods utilized in this report to investigate potential groundwater transport of tritium away from the Gnome site follow the Lagrangian concept of particle displacement in heterogeneous porous media developed in a series of papers by Dagan $(1982,1984,1987)$. This approach treats the solute as a collection of particles transported by groundwater under advection, dispersion, and other chemical and physical processes and results in first-order approximations of solute behavior. The first method used here is a travel-time technique which provides approximations of tritium arrival times and mass at the Pecos River. The second method is an analytical solution for the first two moments of tritium displacement in space. These moments describe the mean location of the tritium mass (the center of mass) and the spreading of that mass about the mean location. The following is a general description of these methods. The reader is referred to Appendix A for a more detailed treatment of the theory.

Groundwater velocity is related to the transmissivity field through a modified form of the Darcy equation, $U=T_{g} J / b n$, where $U$ is the mean groundwater velocity, $T_{g}$ is the geometric mean of transmissivity, $J$ is the mean hydraulic gradient, $n$ is the mean effective porosity, and $b$ is the mean aquifer thickness. If the parameters on the right-hand side of the modified Darcy equation are $\log$-normally distributed, then so is $U$ and the estimate of the mean velocity is $\mu_{\ln } U=\mu_{\ln } T+\mu_{\ln } J$ $-\mu_{\ln b}-\mu_{\ln n}$. The variance of $U, \sigma^{2} \ln U$, is the sum of the variances of $\ln T, \ln J, \ln b$, and $\ln n$ (and possible correlations between these parameters), and represents the magnitude of the uncertainty in the estimate of $U$ contributed by the estimation errors of $T, J, b$, and $n$.

The travel-time method describes particle movement by particle arrival time at a plane perpendicular to the direction of mean flow. This arrival time $t$ is defined at a distance $L$ from the injection point in a steady-state, spatially variable velocity field having mean velocity $U$. Aquifer heterogeneity is included and represented by the variance of log-transmissivity $\sigma^{2} \ln T$, and the transmissivity integral scale $\lambda$. The combination of the spatial variability of aquifer properties and the uncertainty in the estimates of these properties means that the arrival time at $L, t(L)$, is a random function described by a probability density function (pdf). In the case of pure advection, the travel time to the distance $L$ from the source is given by $t(L)=L / U$, which can be described by a travel-time pdf of log-normal form that is modified to account for radioactive decay of tritium. The travel-time distribution is therefore a result of the variability in the mean velocity' $U$ caused by uncertainty in the estimates of the parameters of the Darcy equation and the spatial variability of transmissivity. As will be seen later, radioactive decay also plays an important role in the distribution of tritium travel times. 
The travel-time method is important because it can be used to describe solute mass flux as a function of time at a given distance where exposure or access to groundwater is possible. This approach is particularly applicable to problems that involve risk assessment at the accessible environment (Andricevic et al., 1994). The second method utilized here, the analysis of tritium spatial moments, describes the movement of tritium mass in space at given times and is most useful for studying the transport of the bulk of the tritium mass. Ensemble averages of these spatial moments can be made by averaging many stochastic realizations of the plume created numerically by the particle tracking random walk (PTRW) method but the computer- and data-intensive nature of that method was not considered appropriate for this study. Dagan (1989) presented an analytical solution for the first two moments of displacement of a nonreactive solute in a heterogeneous aquifer from an instantaneous point source. Like the travel-time approach described above, this solution represents the spatially variable transmissivity field as a two-dimensional field that can be statistically characterized by $\mu_{\ln T}, \sigma^{2} \ln T$, and $\lambda$, with a $\log$-normal distribution of transmissivity.

The first moment of displacement describes the mean location (center of mass) of the tritium and is simply a linear function of time, $X_{L}=U t$. The second moments describe the spreading of mass about the mean location. For the two-dimensional case, the spreading is described in the direction of mean groundwater flow (longitudinal spreading) and perpendicular to the mean groundwater flow (transverse spreading). Unlike the travel-time method, uncertainty in the parameters of the flow equation are not directly incorporated in the calculation of the spatial moments; therefore, tritium spreading will be slightly underestimated by this method.

It should also be noted that Dagan's original development of the Lagrangian concept of particle displacement in heterogeneous porous media assumed a variance of transmissivity that is lower than the variability often observed in the field. In recent years, however, extensive numerical simulations have shown that Dagan's solution is very robust with respect to the variance (for example, see Tompson, 1993). As will be discussed later in this report, the available data suggest that the variability in transmissivity in the vicinity of Gnome is very high. This will not seriously impact the validity of the results because the intent was to provide only first-order approximations of tritium transport. In addition, any study of contaminant transport at Gnome is limited from the start by the lack of hydrogeologic data in the vicinity of the site, such that the results are probably more strongly influenced by data limitations. Note that parameter values and results presented here are reported to three significant figures to be consistent with the data. This does not suggest that the results are accurate to this level.

\section{APPLICATION AND RESULTS}

This analysis focuses on transport of radionuclides in only the Culebra dolomite because this was the unit at the Gnome site in which radioactive tracers were known to be directly injected. As a result of the low permeability of the evaporites that bound the Culebra dolomite above and below, it is assumed that the radionuclides have remained confined to the dolomite. Therefore, the 
dissolution residue at the base of the Rustler Formation is not considered important to the transport of radionuclides away from the tracer site and is not included in this analysis. Groundwater transport of radionuclides from the Project Gnome nuclear cavity and underground workings is not specifically included here because of great uncertainties in the radioactive source term and mechanisms of release to the Culebra dolomite. Also, because the radionuclides from the tracer test were injected directly into the aquifer (rather than radionuclides from the nuclear cavity migrating through the chimney, shaft, or boreholes to the aquifer), tracer test material is believed to present the greatest potential for off-site transport of radionuclides through the Culebra (Chapman and Hokett, 1991).

The hydrogeologic parameters required for the analysis, and how their values were estimated, are discussed in the following sections, followed by a discussion of the results. The values used in the analysis are presented in Table 2. The primary sources of data included hydrogeologic reports prepared for Project Gnome, reports presenting the results of the radioactive tracer studies, and site characterization reports for WIPP.

Table 2. Values of Input Parameters. Data values and their sources are discussed in the text.

\begin{tabular}{|c|c|c|c|}
\hline Parameter & \multicolumn{3}{|c|}{ Value } \\
\hline Transmissivity $T$ & $T$ Dataset 3 & TDataset 2 & Well USGS-1 \\
\hline Average, $\overline{\mathrm{X}}_{T}\left(\mathrm{~m}^{2} / \mathrm{s}\right)$ & $4.93 \times 10^{-4}$ & $2.91 \times 10^{-4}$ & $5.50 \times 10^{-4}$ \\
\hline Geometric mean, $T_{g}\left(\mathrm{~m}^{2} / \mathrm{s}\right)$ & $1.43 \times 10^{-4}$ & $5.33 \times 10^{-5}$ & $5.48 \times 10^{-4}$ \\
\hline Mean, $\mu_{\ln T}\left(\ln \mathrm{m}^{2} / \mathrm{yr}\right)$ & 8.41 & 7.43 & 9.76 \\
\hline Variance, $\sigma^{2} \ln T$ & 5.0 & 5.5 & 5.0 (assumed) \\
\hline \multicolumn{4}{|c|}{ Transmissivity Correlation Scale, $\lambda(\mathrm{m})$} \\
\hline & 6000 & & \\
\hline \multicolumn{4}{|l|}{ Porosity $n$} \\
\hline Average, $\bar{X}_{n}$ & 0.15 & & \\
\hline Mean, $\mu_{\ln n}$ & -1.90 & & \\
\hline Variance, $\sigma^{2} \ln n$ & 0.06 & & \\
\hline \multicolumn{4}{|l|}{ Hydraulic Gradient, $J$} \\
\hline Average, $\overline{\mathrm{X}}_{J}$ & $2.27 \times 10^{-3}$ & & \\
\hline Mean, $\mu_{\mathrm{In} J}$ & -6.09 & & \\
\hline Variance, $\sigma^{2} \ln J$ & 0.0 & & \\
\hline \multicolumn{4}{|l|}{ Aquifer Thickness, $b$} \\
\hline Average, $\bar{X}_{b}(\mathrm{~m})$ & 8.12 & & \\
\hline Mean, $\mu_{\ln b}$ & 2.08 & & \\
\hline Variance, $\sigma^{2} \ln b$ & 0.03 & & \\
\hline
\end{tabular}


Horizontal groundwater flow within the Culebra dolomite is assumed to be the primary pathway for transport of the radionuclide tracers to the accessible environment. Because the unit is relatively horizontal and of uniform thickness (Cooper and Glanzman, 1971), it is assumed that flow and transport within it is two dimensional and horizontal. Isotropic conditions are also assumed to simplify the analysis, although little information is available on fracture orientations and related groundwater flow directions. Likewise, the Culebra is simulated as a single-porosity system with porosity equal to the combined matrix and fracture porosity. Groundwater in the Culebra dolomite is accessible to the surface environment as regional discharge in alluvial deposits adjacent to the Pecos River, approximately $11.3 \mathrm{~km}$ downgradient from the tracer test site. Several wells also access the Culebra in the region between the tracer test site and the Pecos River, although not directly downgradient.

\section{Hydraulic Gradient}

The hydraulic gradient required for this analysis can be arrived at by several methods. Local values include $4.2 \times 10^{-4}$, based on water-level measurements in Gnome test holes USGS-1 and

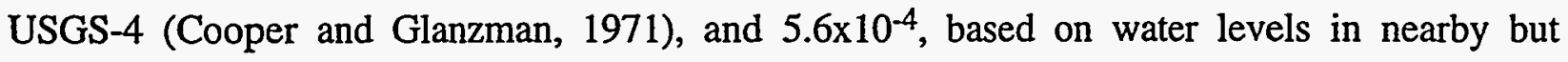
upgradient wells (H-7 and USGS-8) reported in Cauffman et al. (1990). A regional gradient of $2.56 \times 10^{-3}$ was suggested by Cooper and Glanzman (1971), but the area included in the region was not defined. Because the present study focuses on transport on the scale of kilometers, specifically between Gnome and the Pecos River, the hydraulic gradient used here is based on the head difference in the Culebra dolomite between Gnome and the nearest postulated point of discharge to the Pecos River (Figure 3). Based on a head difference of $25.6 \mathrm{~m}$ over a distance of $11.3 \mathrm{~km}$, the hydraulic gradient is estimated to be $2.27 \times 10^{-3}$. The uncertainty in the estimate of hydraulic gradient is assumed to be zero.

\section{Porosity}

Despite its fractured structure, the Culebra dolomite is simulated here as a single-porosity system with porosity equal to the combined matrix and fracture porosity. This approximation is based on the work of Reeves et al. (1987), who concluded that transport times from WIPP in the Culebra dolomite can be approximated using this assumption. Flow modeling studies at WIPP have also been based on this assumption (LaVenue et al., 1990).

Analysis of core samples from the Culebra dolomite at and near WIPP are reported by Kelley and Saulnier (1990). Helium porosity determinations on 79 cores from 21 wells resulted in an arithmetic mean and standard deviation of 0.15 and 0.05 , respectively. Results of water-resaturation-porosimetry showed a near 1:1 correlation with the results of the helium-porosity determinations. Although increasing halite dissolution westward from WIPP suggests higher fracture porosity, analysis of the 23 cores from wells in the region of dissolution resulted in the same mean porosity but a slightly lower 


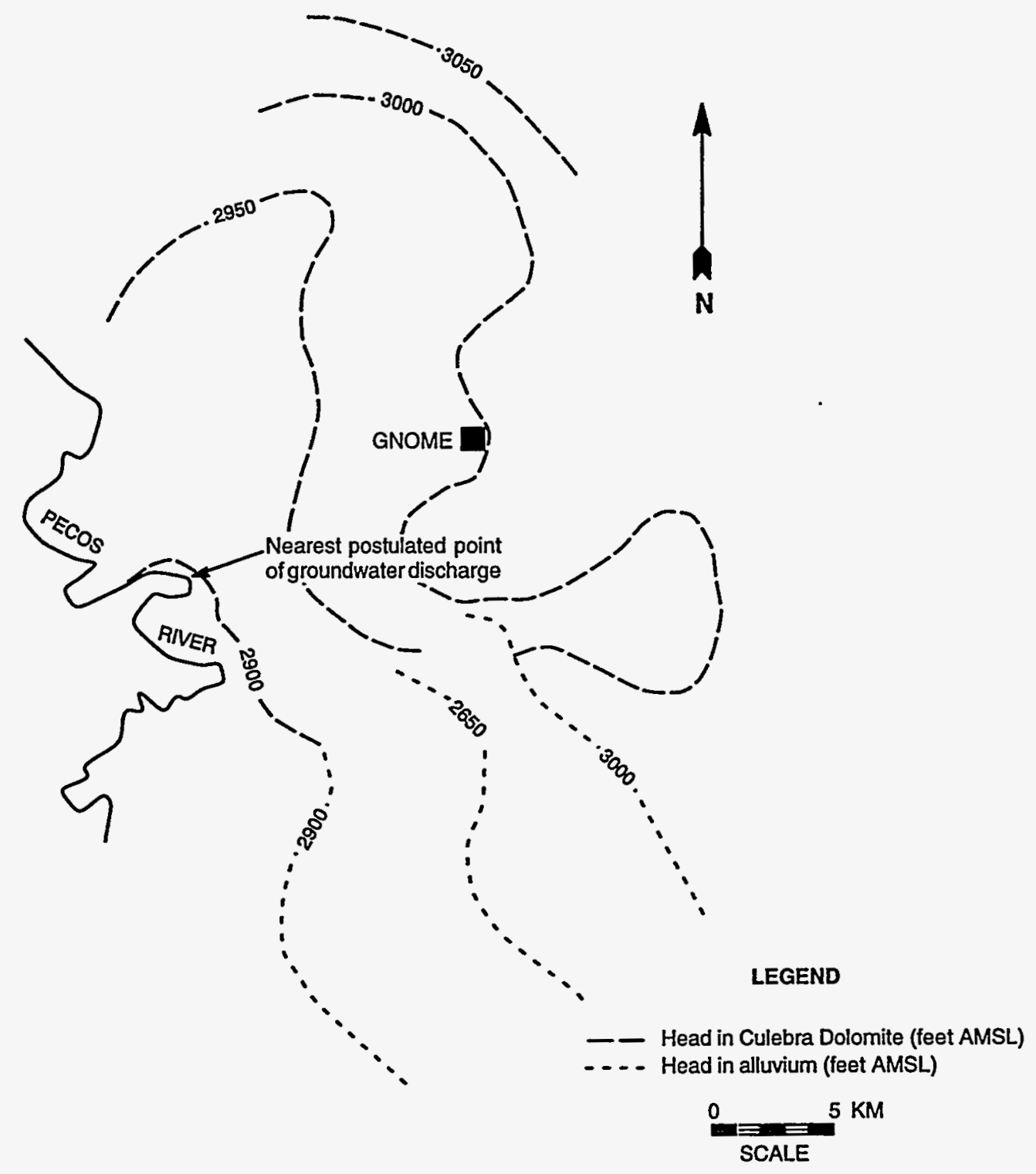

Figure 3. Potentiometric surface in the vicinity of Gnome (after Cooper and Glanzman, 1971). The nearest postulated point of groundwater discharge to the Pecos River is $11.3 \mathrm{~km}$ southwest of Gnome.

standard deviation of 0.045. Analysis of block samples of Culebra dolomite collected during Gnome shaft excavation resulted in an estimate of effective porosity of 0.10 (Cooper and Glanzman, 1971), although the methods of analysis, the number of porosity tests conducted, and the range of porosity values were not reported. Based on the results of the recirculating tracer test at Gnome, Grove and Beetem (1971) calculated an effective porosity of 0.12 . The mean porosity determined from the WIPP studies, 0.15 , is used in this analysis. An error in the porosity measurements of $+/-25 \%$ is assumed, leading to an uncertainty in the log-porosity estimate of 0.06 . 


\section{Thickness}

The distribution of log-thickness was based on WIPP-related data reported in Cauffman et al. (1990). Analysis of the untransformed data from all locations (41 points) and locations within the region of halite dissolution (20 points) resulted in arithmetic means of 7.57 and $7.78 \mathrm{~m}$, respectively. A slight trend of increasing Culebra thickness was observed from northeast to southwest across the site; therefore, the higher mean log-thickness was used in the analysis. Uncertainty in the estimate of log-thickness for both data sets is 0.03 , the variance about $\mu_{\ln b}$.

\section{Transmissivity}

Three sets of transmissivity data for the Culebra dolomite in the vicinity of Gnome were evaluated by variogram analysis (the data are presented in Appendix B and the variograms in Appendix C). Note that these data are based on hydraulic tests specially designed to estimate $T$ of the Culebra, which was isolated for testing through the use of inflatable packers. Dataset 1 incorporated all $41 T$ values reported for the vicinity of WIPP (Cauffman et al., 1990). Dataset 2 includes only the $20 T$ values greater than $1.0 \times 10^{-6} \mathrm{~m}^{2} / \mathrm{s}$, which was suggested by Lappin (1988) as being indicative of fractured Culebra dolomite and roughly coincides with the region of halite dissolution. Dataset 3 includes only the $11 T$ values located in the region of halite dissolution as defined by Snyder (1985). The well locations and their relation to hydrogeologic features are shown in Figure 4. Results of statistical and variogram analysis of the log-transformed data sets are presented in Table 3 . These analyses demonstrate that the mean value of $T\left(\mu_{\ln \tau}\right)$ increases significantly as the included data points are progressively restricted to the region of halite dissolution. Because groundwater flow in the vicinity of Gnome is directed toward the west and southwest, in the direction of increasing halite dissolution, the highest mean value of Culebra $T$ is used in the travel-time analysis. Using high $T$ values results in relatively higher mean groundwater flow velocities, leading to more conservative estimates of contaminant transport. Note that the $\mu_{\ln T}$ value of 9.76 for well USGS-1, which is located at Gnome, is at the high end of the range of transmissivities in the region of halite dissolution (Table 2). Although this single value cannot represent the range of transmissivities in the area of investigation, it is included in the analysis to investigate the implications of very high groundwater velocity.

Table 3. Results of Variogram Analysis of Log-Transmissivity Data

\begin{tabular}{lccc}
\hline \hline & Dataset 1 & Dataset 2 & Dataset 3 \\
\hline Description & All data points & $T>10^{-6} \mathrm{~m}^{2} / \mathrm{s}$ & Region of halite dissolution* \\
Number of points & 41 & 20 & 11 \\
Mean, $\mu_{\ln T}\left(\ln \mathrm{m}^{2} / \mathrm{yr}\right)$ & 4.55 & 7.43 & 8.41 \\
Variance, $\sigma^{2} \ln T$ & 16.5 & 5.5 & 5.0 \\
Correlation Scale, $\lambda(\mathrm{m})$ & 12,000 & 6,000 & 6,000 \\
\hline
\end{tabular}

*As defined by Snyder (1985) 


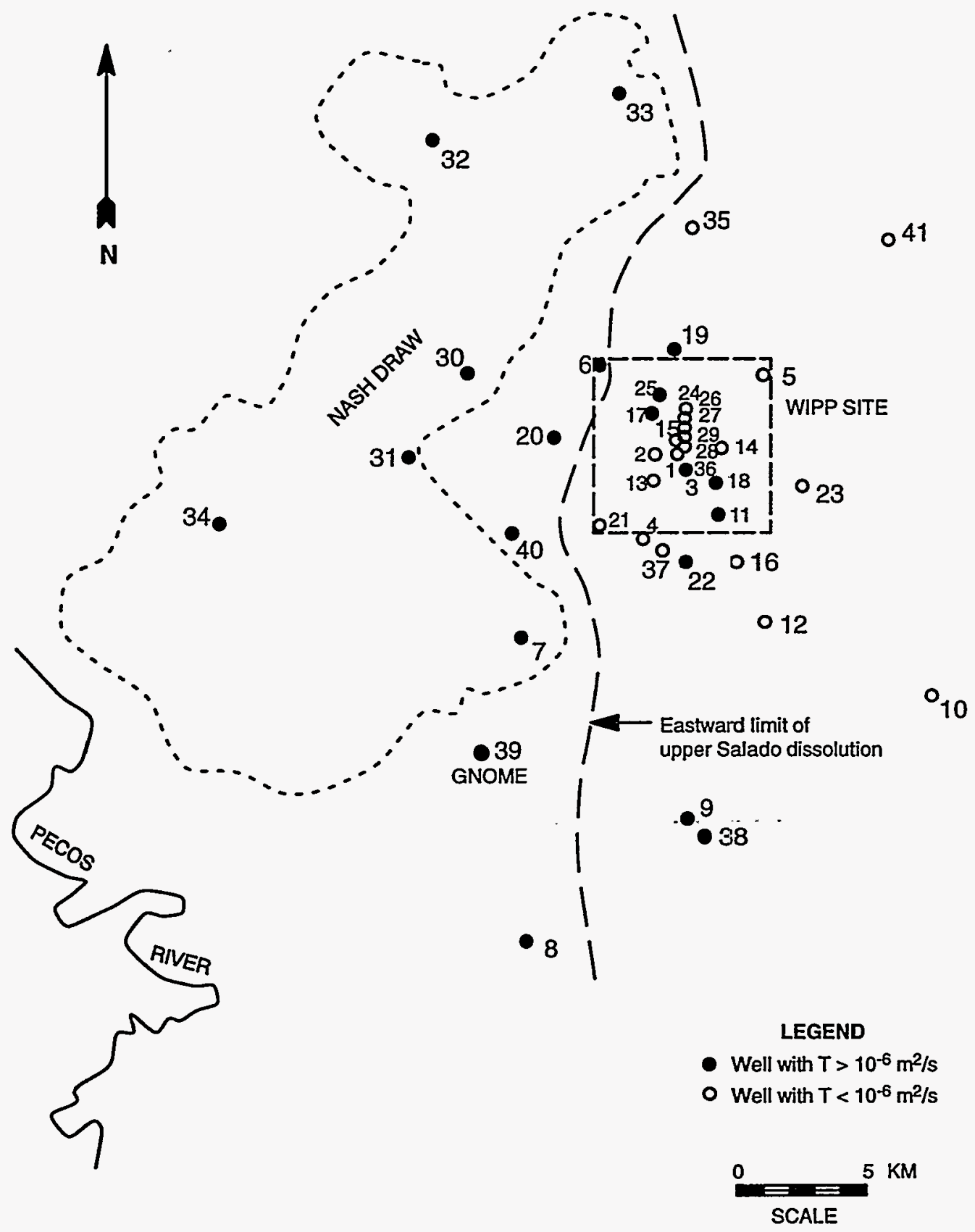

Figure 4. Locations of wells in the vicinity of Gnome used for analysis of the transmissivity field. Well numbers refer to data presented in Appendix B. Three datasets were analyzed: Dataset 1 includes all 41 wells shown, Dataset 2 includes only the 20 wells having $T$ values greater than $10^{-6} \mathrm{~m}^{2} / \mathrm{s}$ (dark circles), and Dataset 3 includes only the 11 wells located in the region of dissolution in the upper Salado Formation (to the left 
It is noteworthy, particularly for Dataset 1 , that no nugget effect was identified in the $T$ fields. Fractured rocks often exhibit significant nugget effect as a result of small-scale variability (Hoeksema and Kitanidis, 1985). For example, if two boreholes are crilled in near proximity in a fractured aquifer it is unlikely that both would intersect the same fractures in such a way that the observed transmissivities would be the same. The lack of a nugget effect in Datasets 2 and 3 was not surprising because the minimum well spacing (approximately $1.5 \mathrm{~km}$ ) in the region of halite dissolution is too large to adequately characterize small-scale fluctuations. However, absence of a nugget effect causes all observed variability in the $T$ field to be classified as correlated variance (the "sill" on the variograms in Appendix C), which produces the variability in the groundwater velocity field. If a portion of the observed variability is actually nugget, as is often the case in fractured rocks, both the correlated variance in $T$ and the resultant variability in the velocity field would be reduced.

The very high variability observed in Dataset 1 is a result of the wide range in $T$ values that exists across the vicinity of the WIPP site. This variability is lower in Datasets 2 and 3 because the range in $T$ is reduced by including only subsets of Dataset 1 . The variance estimated from Datasets 2 and 3 (a value of 5.0) was used for the $\log$-transformed $T$ field. Although this value is higher than the mean value of total variance of $T$ for consolidated rock aquifers (3.48) reported by Hoeksema and Kitanidis (1985), it does fall within their total range (0.034 to 16.3). Also, because a nugget effect was not identified in Datasets 2 and 3, all the observed variability is assumed to be spatially correlated.

The uncertainty in the estimate of $\log -T$ is a function of the variability between the means of the stochastic realizations of the $T$ field. This uncertainty was calculated analytically from (A.6) to be approximately 1.0 for all cases.

\section{Spatial Correlation Scale}

The correlation scale of transmissivity $(6,000 \mathrm{~m})$ was estimated from the variogram analysis of Datasets 2 and 3. This value falls within the total range of correlation scales of $T$ for consolidated rock aquifers (1,400 to $44,700 \mathrm{~m}$ ) reported by Hoeksema and Kitanidis (1985), though it is somewhat less than their estimated mean value of $17,400 \mathrm{~m}$. It should be noted, however, that calculation of correlation scale is strongly influenced by the scale of the investigation, the spacing of the data points, and the interpretation of the variograms, and therefore must be considered approximate.

\section{Mean Groundwater Velocity}

The mean groundwater velocities, $U$, estimated from equation (A.2) are 8.36, 3.28, and 32.2, $\mathrm{m} / \mathrm{yr}$ for Datasets 3 and 2 and well USGS-1, respectively (Table 1). Velocities from Datasets 3 and 2 are within the range of velocities ( 2 to $10 \mathrm{~m} / \mathrm{yr}$ ) calculated for the Culebra dolomite in the Gnome 
area using a three-dimensional finite-difference groundwater flow model of the WIPP area (LaVenue et al., 1990). By incorporating the uncertainties in the estimates of the hydraulic parameters through relation (A.5), the distribution of uncertainty in $U$ at any given point in the domain can be calculated (Figure 5). Although low velocities are most probable, the strong tailing toward high velocities suggests that relatively high velocities are also possible. For the most probable case (Dataset 3), velocities at least as high as $30 \mathrm{~m} / \mathrm{yr}$ appear to be a significant component of the velocity distribution. This velocity distribution fits the conceptual model of flow in fractured media in which groups of fractures form preferred pathways of flow. Channelization of flow in these preferred pathways contributes to the high-velocity component of the groundwater flow velocity distribution.

Also note from Figure 5 that due to the log-normal velocity distribution, the mean value of $U$ does not coincide with the most probable velocity. For Dataset $3, U$ is $8.36 \mathrm{~m} / \mathrm{yr}$, but the most probable velocity is approximately $3.5 \mathrm{~m} / \mathrm{yr}$.

\section{Travel-Time Distributions}

The travel-time distributions incorporate both uncertainty in the estimates of the hydraulic parameters in the Darcy equation and the spatial variability observed in the transmissivity field. The travel-time curves are pdfs and are presented in terms of tritium mass passing the control plane per

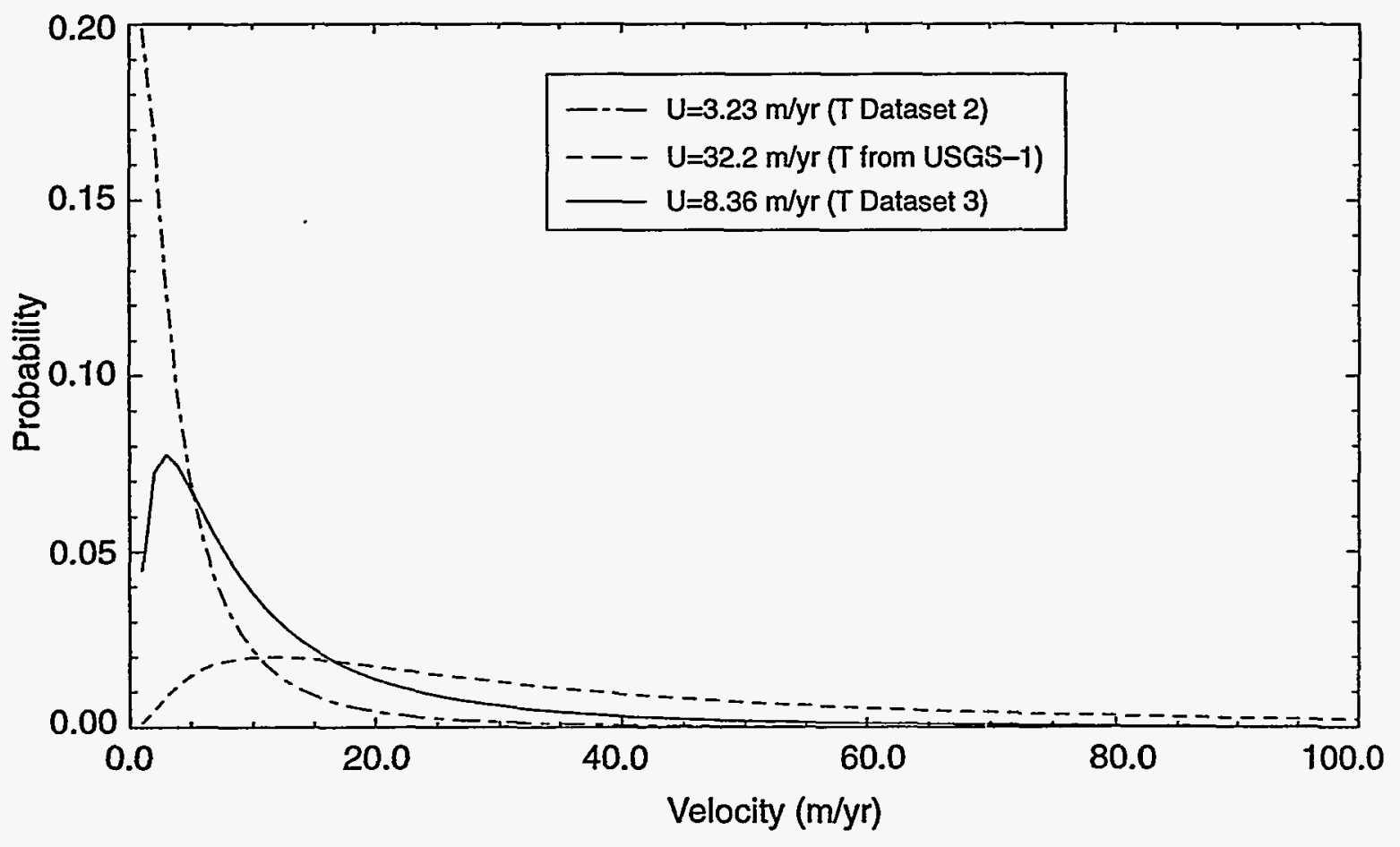

Figure 5. Distribution of uncertainty in mean advective groundwater velocity, $U$. 
year after the tracer tests. The travel-time pdfs for tritium and the water mass alone, both simulated under the conditions of the best estimates of all parameters, are compared in Figure 6. Note that the peak of the tritium pdf corresponds to a considerably shorter travel time than the peak of the water mass pdf; 11 years for the tritium and 70 years for the water mass. This is because long groundwater travel times allow more time for tritium to decay at its relatively short half-life of 12.4 years. Therefore, due to radioactive decay, the bulk of the tritium mass decays in the time required to travel $11.3 \mathrm{~km}$ and only a fraction of the total tritium mass reaches the accessible environment. For the purpose of this report, radioactive decay is said to remove the longer times from the travel-time distribution. The remaining travel-time distributions presented here incorporate tritium radioactive decay and are calculated for a control plane at the Pecos River, a downgradient distance of $11.3 \mathrm{~km}$.

The pdfs presented in Figure 6 also clearly illustrate the variability in estimates of travel time and migration distance caused by uncertainty and spatial variability in the input parameters. These factors lead to downgradient spreading of tritium from the center of mass, causing the tritium to be transported farther than predicted by the mean advective flow velocity. Note that a mean advective flow velocity, $U$, of $8.36 \mathrm{~m} / \mathrm{yr}$ causes the center of mass to migrate only $260 \mathrm{~m}$ in 31 years. However, the travel-time calculations suggest that some mass will have arrived at the Pecos River before this

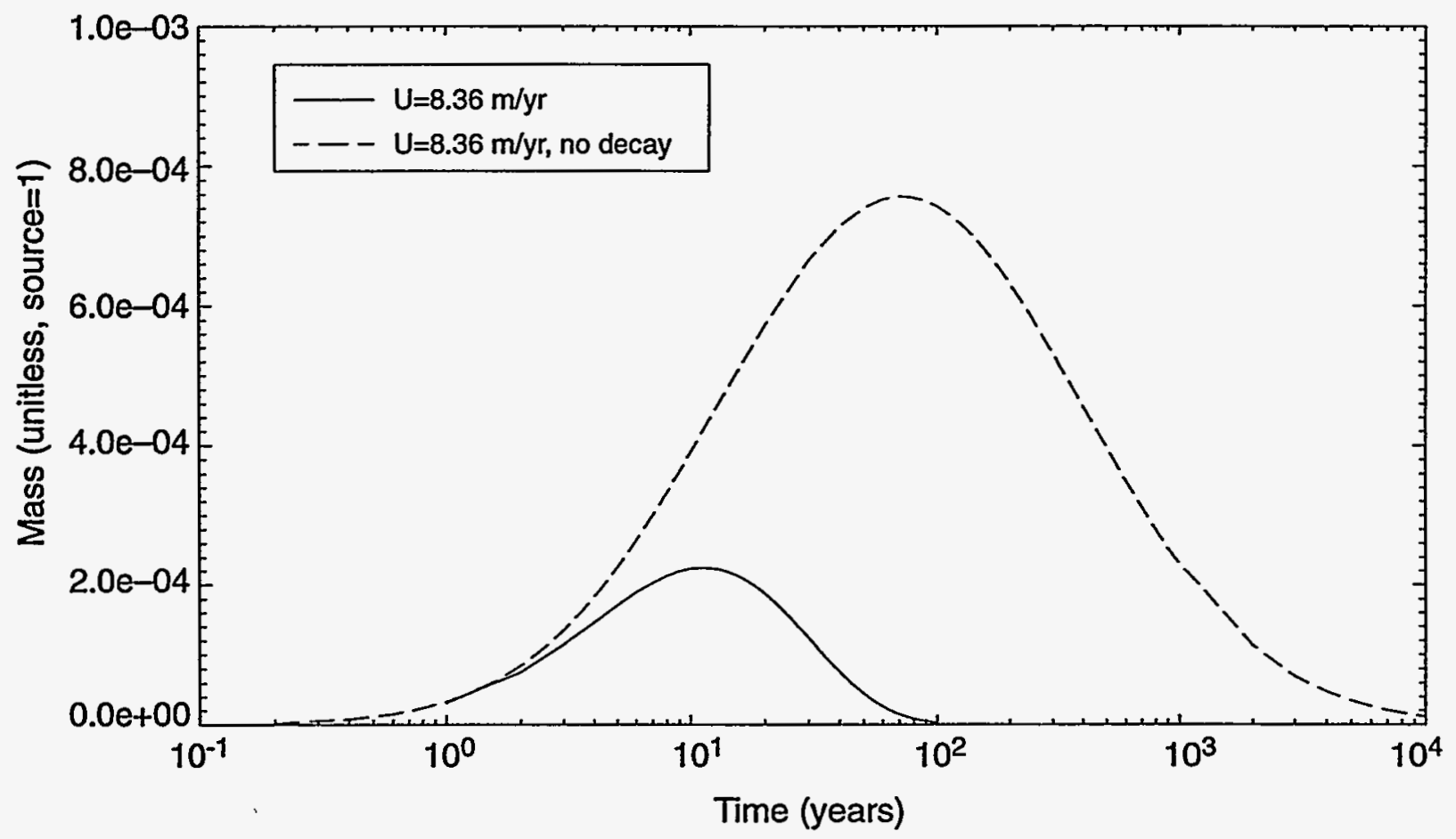

Figure 6. Travel-time distribution at the Pecos River with and without radioactive decay of tritium. The travel times without decay represent advection of the water mass. 
time as indicated by the leading edges of travel-time curves in Figure 6. By the time the center of mass arrives at the Pecos River (1,300 years), virtually all mass will have been lost to radioactive decay.

The sensitivity of the travel-time pdf to an approximate one order-of-magnitude range in $\ln T$ is shown on Figure 7. The low extreme of the range represents the mean of wells in the vicinity of WIPP having transmissivity values greater than $1.0 \times 10^{-6} \mathrm{~m}^{2} / \mathrm{s}$, while the high extreme represents the value estimated at well USGS-1 by Cooper and Glanzman (1971). The best estimate represents the mean of $\ln T$ in the region of halite dissolution. The order-of-magnitude range in $\ln T$ leads to a range in arrival times of 6 to 15 years for the peak tritium mass at the Pecos River, with the shortest peak arrival time corresponding to the highest $T$. The range in $\ln T$ also results in a range in mass arriving at the Pecos River of over one order-of-magnitude. These very short travel times result from the removal of long travel times by radioactive decay and the combination of the spatial correlation scale and high variability assigned to the $T$ field. As discussed above, the high variability in $T$ produces a highly variable groundwater velocity field with a significant component of high velocities. Because the Culebra dolomite demonstrates important spatial correlation, regions of high velocity are "persistent" in the velocity field, contributing to the relatively short travel times

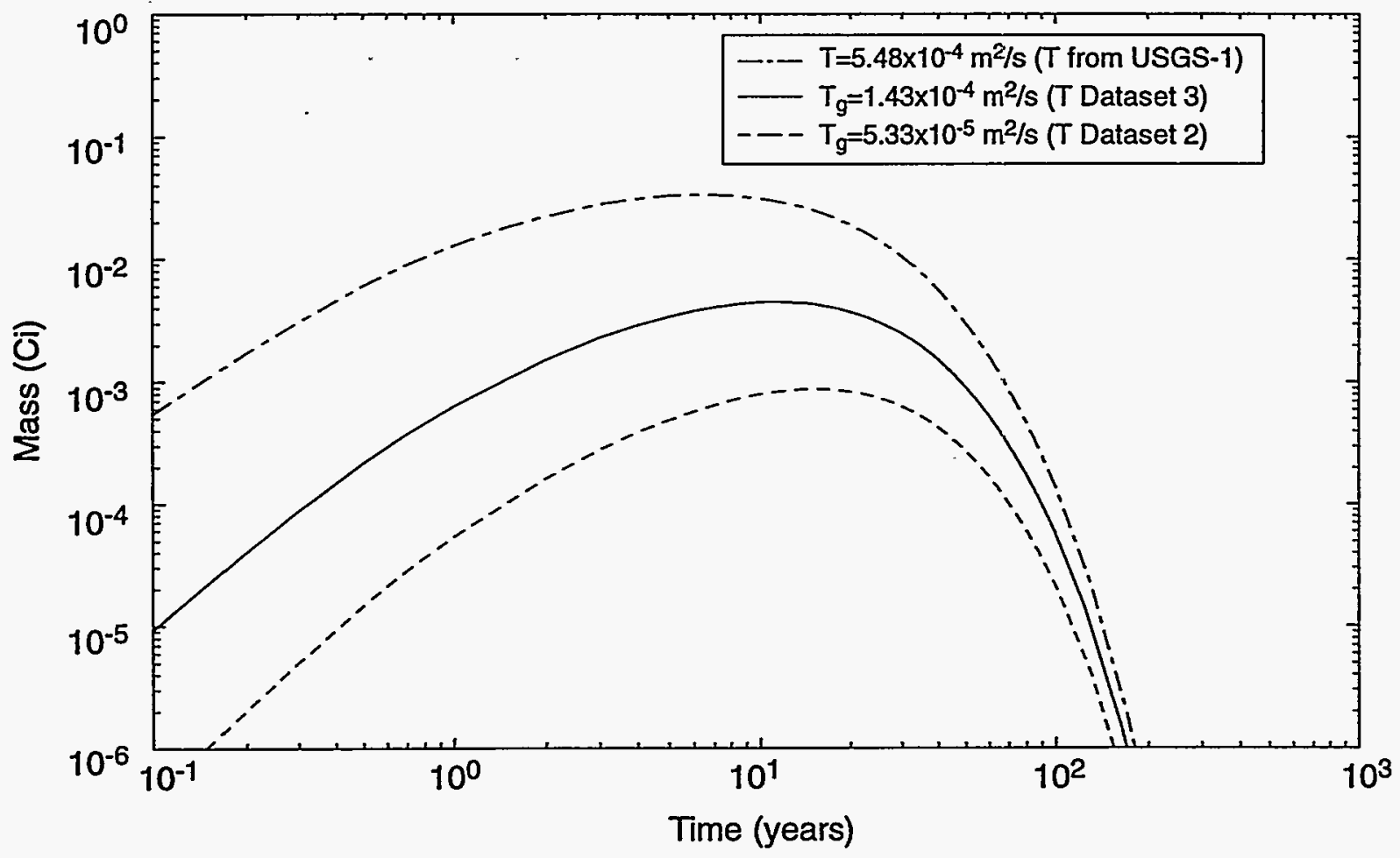

Figure 7. Sensitivity of the travel-time distribution at the Pecos River to log-transmissivity, $\ln T$. Source mass is $20 \mathrm{Ci}$ of ${ }^{3} \mathrm{H}$. 
estimated here. It should also be noted that the relatively high mass and low travel times produced by the highest $T$ are a result of the combination of the high $T$ estimated at USGS- 1 and the high spatial variability in $T$. The transmissivity estimated at USGS-1 falls near the upper extreme of the transmissivity distribution, and therefore represents only a single point on the distribution, not the mean. Assuming that this value is the mean, and including the high spatial variability, results in a velocity distribution that includes very high, and probably unrealistic, groundwater velocities. This value was included here not to predict likely travel times but to demonstrate how travel times are affected by values of transmissivity chosen for the analysis. Rather, the distribution of transmissivity in the Culebra dolomite in the region of halite dissolution is best represented by the observed mean of $\ln T\left(\mu_{\ln T}=8.41\right)$ in conjunction with its observed spatial variability.

Sensitivity of the travel-time pdf to spatial variability in $T$ was investigated by varying the value of $\sigma^{2} \ln T$. The probable maximum range of correlated variability is based on the variability in $\ln T$ reported by Hoeksema and Kitanidis (1985) for consolidated aquifers. An estimate for $\sigma$ of 1.29 was obtained from the reported range of 0.0 to 5.17 ( $\sigma \approx 1 / 4$ [range]), resulting in a range of variability $\left(\sigma^{2} \ln T \pm 2 \sigma\right)$ of 2.41 to 7.58 . Uncertainty in the estimate of $\sigma^{2} \ln T$ for the Culebra dolomite in the area of halite dissolution was estimated from Dataset 3 and relation (A.6). This uncertainty is 1.39 and results in an estimated range of $\sigma^{2} \ln T$ between 3.61 and 6.39. Note that the upper limits of both of these ranges in $\sigma^{2} \ln T$ lie above the maximum variability reported by Hoeksema and Kitinidis (1985), and that the correlated variance estimated from the WIPP data in the area of halite dissolution is also very near this maximum. Therefore, variability is much more likely to be lower than that used in this study, rather than greater. Increasing variability above the best estimate of 5.0 did not have a significant impact on the arrival time or magnitude of the peak mass (Figure 8). As variability decreases, the peak of the travel-time pdf is shifted toward longer times and the maximum mass reaching the control plane declines. This is because reducing the variability progressively removes the extreme values from the velocity distribution that in turn lead to extreme values of travel-time. For a rapidly decaying species such as tritium, the long travel times are removed by decay so it is primarily the short travel times that are impacted by reclucing variability (Figure 8). At 31 years, changing $\sigma^{2} \ln T$ through the maximum probable range caused about a 2 times change in mass. By virtually eliminating spatial variability, the mass was reduced by over an order of magnitude, although this case is highly unlikely considering the variability in transmissivity observed in the Culebra dolomite.

The value of the spatial correlation scale was varied through similarly estimated appropriate ranges. The maximum probable range was estimated from the variability of $T$ correlation scale reported by Hoeksema and Kitinidis (1985) for consolidated aquifers. This range caused the estimated minimum $\lambda$ for the Culebra to be less than zero, so the minimum reported value of $1.45 \mathrm{~km}$ 


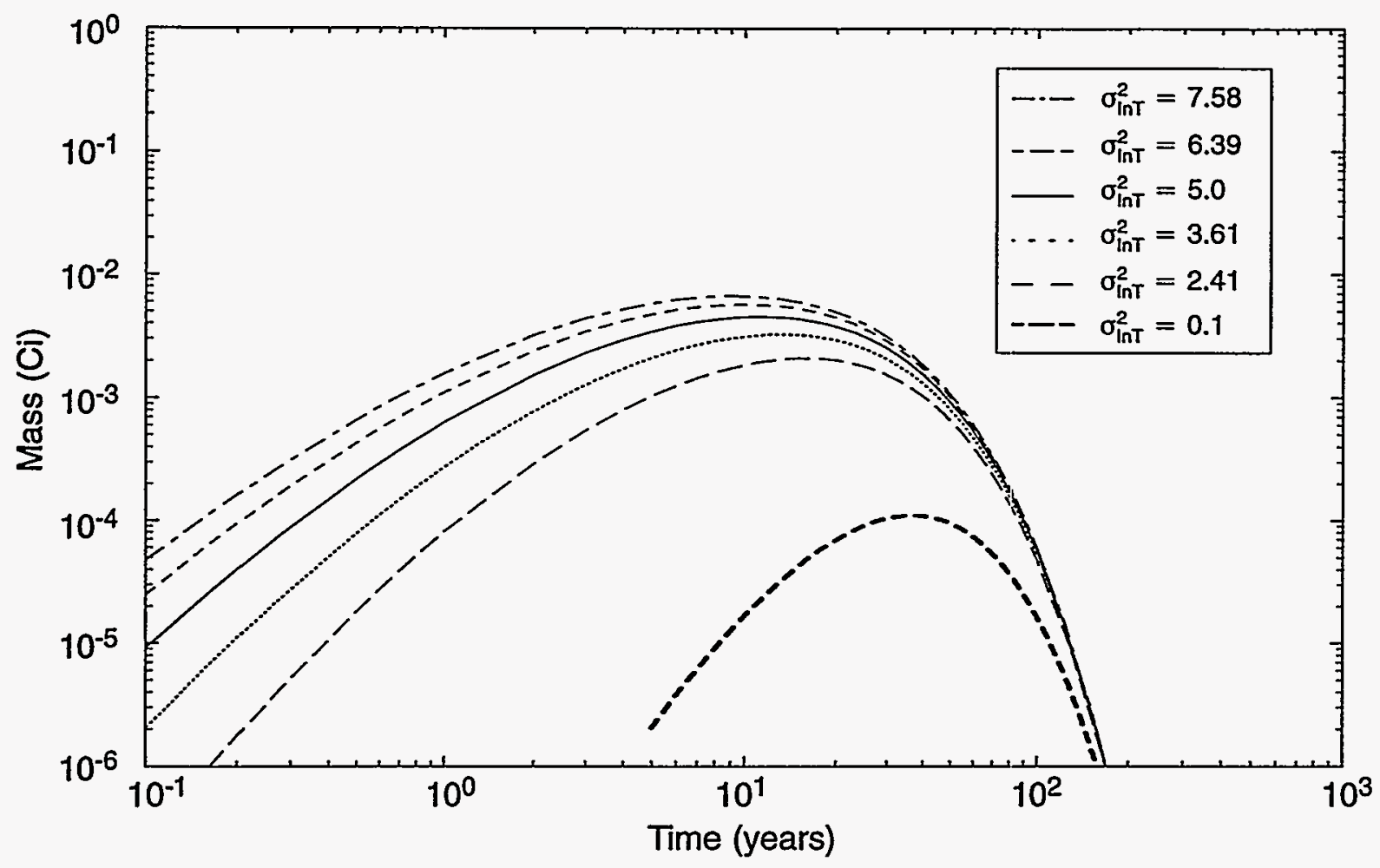

Figure 8. Sensitivity of the travel-time distribution at the Pecos River to correlated spatial variability, $\sigma^{2} \ln T$. Source mass is $20 \mathrm{Ci}$ of ${ }^{3} \mathrm{H}$.

was utilized in the sensitivity analysis. The maximum value was estimated to be $27.6 \mathrm{~km}$. A second range for $\lambda$ of 3.5 to $8.5 \mathrm{~km}$ was estimated through inspection of the transmissivity variograms for the Culebra dolomite. Reducing the correlation scale causes the travel times to increase and the maximum mass to be reduced (Figure 9) as a result of the decreased spatial persistence of $T$, and therefore $U$. Variation of $\lambda$ through the range representative of the Culebra resulted in a range of mass at 31 years that was similar to the range observed for variance, indicating that these parameters are of similar importance to transport in the Culebra dolomite. Variation through the maximum probable range of $\lambda$ resulted in an almost order-of-magnitude change in mass at 31 years, indicating that spatial correlation is particularly important when spatial variability is high.

Uncertainty in the estimate of mean velocity was investigated by varying the value of $\sigma^{2} \ln U$ through a hypothetical range of magnitude similar to that utilized in the sensitivity analysis of spatial variability. Recall that this parameter represents the sum of the uncertainty in the estimates of all the parameters of equation (A.2), not their spatial variation. The best estimate of $\sigma^{2} \ln U$ was calculated from (A.4) to be 1.08, with the uncertainty in the estimate of $\ln T$ the dominant contributor. The range in $\sigma^{2} \ln U$ was then assumed to be 0.01 to 2.5 . Uncertainty in the estimate of mean velocity appears to have an important impact on peak mass and arrival time (Figure 10), though the arbitrarily chosen 


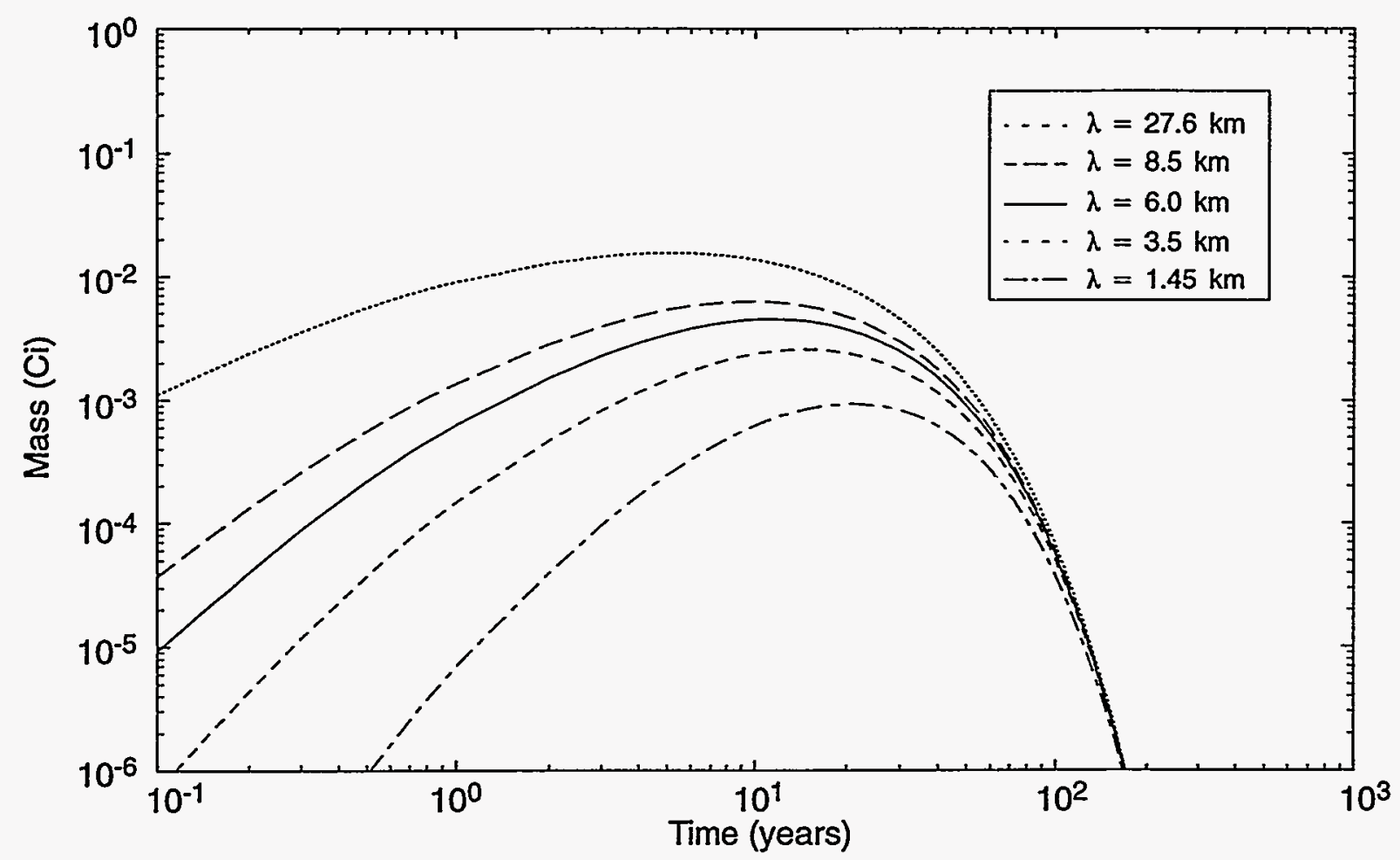

Figure 9. Sensitivity of the travel-time distribution at the Pecos River to spatial correlation scale, $\lambda$. Source mass is $20 \mathrm{Ci}$ of ${ }^{3} \mathrm{H}$.

range may be excessive at the upper extreme because spatial variability was already assumed to be very high. To elaborate, small-scale variability (nugget effect) or uncertainty in the estimate of $\ln$ $T$ was assumed negligible because it could not be identified in the available dataset. Therefore, the total variance is assumed to be composed entirely of the spatially correlated variability $\left(\sigma^{2} \ln T=5.0\right)$ and assuming an uncertainty in $\ln U$ of 2.5 would increase the total variance well beyond the range observed in the field.

The maximum mass reaching the Pecos River per year corresponds to the peak of the travel-time pdf. Based on the best estimates of the parameters presented above, this is approximately $4.5 \times 10^{-3} \mathrm{Ci}$, or about 0.02 percent of the total mass injected during the tracer tests. At the present time (31 years), approximately 0.01 percent of the total mass is reaching the Pecos River annually. Estimates of the concentrations of tritium in groundwater at the Pecos River corresponding to these mass estimates would be highly uncertain because the volume of groundwater over which the mass is distributed is unknown. The groundwater volume is a function of tritium spreading and dilution, both of which are highly uncertain at the distance of the Pecos River, and therefore was not addressed in this study. 


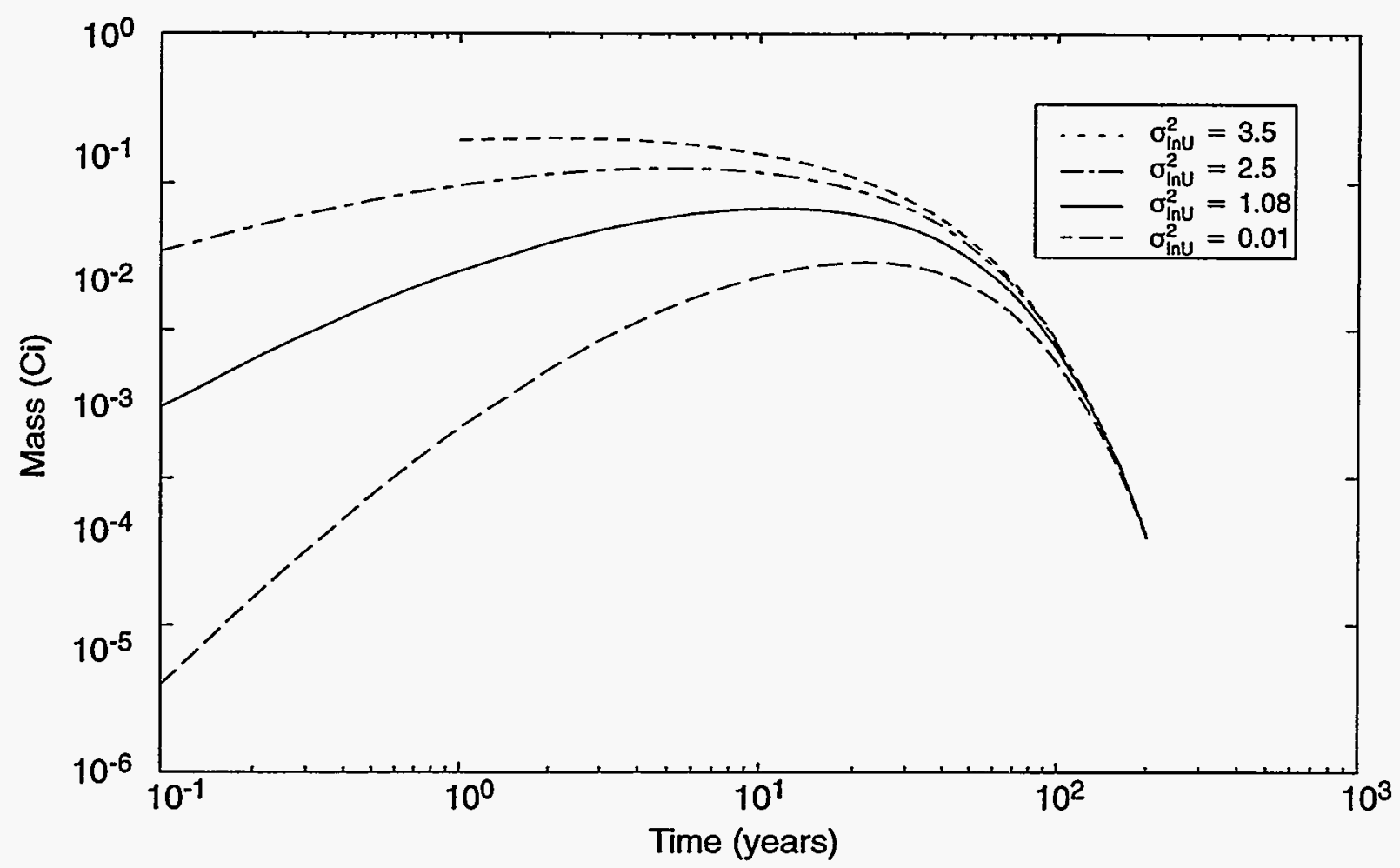

Figure 10. Sensitivity of the travel-time distribution at the Pecos River to uncertainty in mean velocity, $\sigma^{2} l n U$. Source mass is $20 \mathrm{Ci}$ of ${ }^{3} \mathrm{H}$.

\section{Spatial Moments}

An analytical solution for the first two moments of tritium displacement was used to estimate the outer limits of tritium spatial distribution to investigate the near-field behavior of tritium migration. Like the travel-time method applied above, this approach incorporates heterogeneity in the flow field by treating transmissivity as a spatially correlated random field. However, uncertainty in estimation of the parameters of the flow equation are not incorporated; as a result, the spatial moments will underestimate the tritium spreading.

Equations (A.12) and (A.13) provide a method of analytically determining the second moments of tritium displacement to define the outer limits within which all possible realizations of the migrating tritium are located. At any given time, these limits are represented as ellipses centered at the point defined by the first moment (center of mass), and having coordinate axes defined by the second moment (spreading). Note that these ellipses represent ensemble, large-scale transport behavior for comparison purposes only; they do not express the actual distribution of mass within individual realizations of tritium transport. 


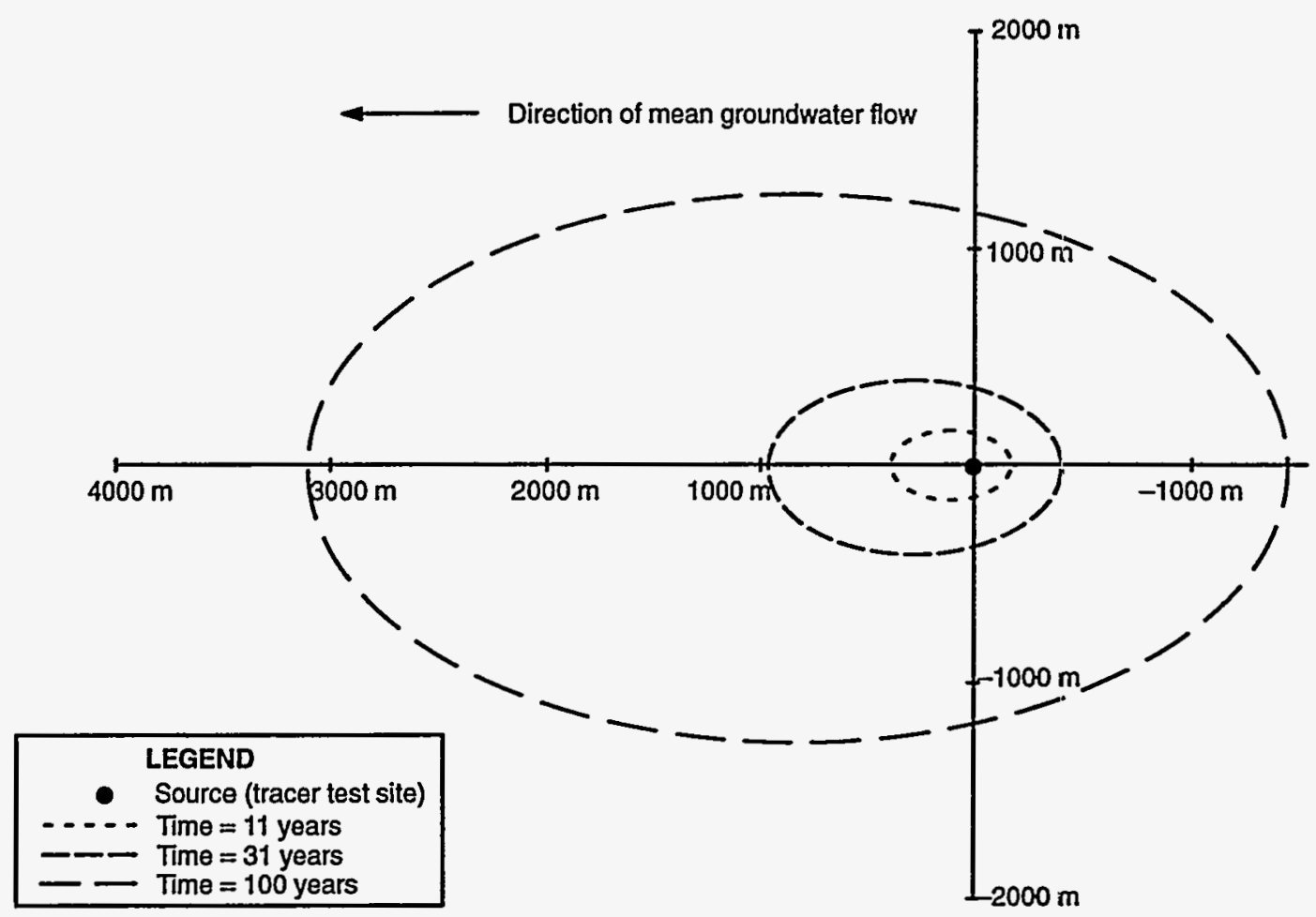

Figure 11. Spatial moments of tritium displacement at 11,31, and 100 years after the tracer test. Spatial moments are expressed as \pm two standard deviations of spreading about the center of mass, which is $90 \mathrm{~m}$ downgradient at 11 years, $260 \mathrm{~m}$ at 31 years, and $830 \mathrm{~m}$ at 100 years.

Tritium spreading is expressed as the square root of the second moment in each coordinate direction, corresponding to one fourth of the coordinate axes of the ellipses. The axes of the ellipses are then each of length $\pm 2 \sigma$ about the center of mass and, therefore represent the outer limits of 95 percent of the tritium mass in these coordinate directions. Assuming a standard normal distribution of mass, 95 percent of the mass will be contained in the ellipse having these dimensions. Figure 11 shows the outer limits of 95 percent of the tritium mass at 11,31, and 100 years. Again, though the magnitude of tritium displacement can be approximated by its spatial moments, the actual distribution of mass within the limits of the elliptical area defined by these moments cannot be ascertained. The tritium is likely concentrated in preferred pathways of migration, such as connected systems of fractures, and therefore estimation of concentrations within the outer limits cannot be justified.

For comparison purposes, the farthest downgradient outer limit is defined here as the tritium "leading edge" and is represented by the point that is $2 \sigma$ downgradient from the center of mass at a given time. In this way, about 95 percent of the tritium mass is behind the leading edge. The relationships of the spatial moments of tritium distribution to the geography in the Gnome vicinity are shown for 31 and 100 years in Figure 12. At the present time ( 31 years), it is estimated that the 


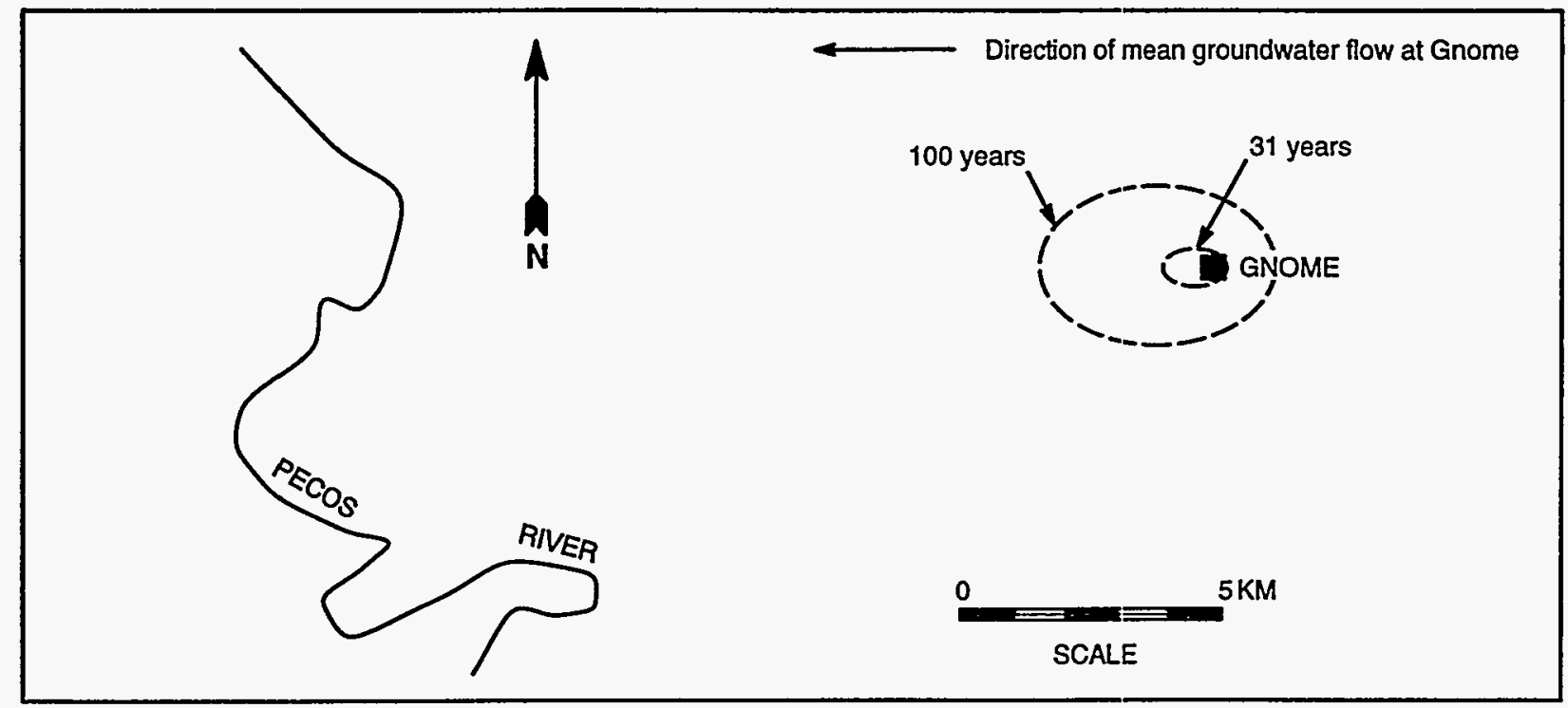

Figure 12. Relation of tritium displacement to geography in the vicinity of Gnome. The ellipses correspond to the 31- and 100-year spatial moments shown in Figure 11. The direction of mean groundwater flow at Gnome is assumed to be to the west (Cooper and Glanzman, 1971).

leading edge is about $1000 \mathrm{~m}$ downgradient of the tracer site and that the center of mass (defined by $U t$ ) is located approximately $260 \mathrm{~m}$ downgradient. The likelihood of a monitoring well intercepting measurable concentrations of tritium in the groundwater is highest within this.area. However, because the distribution of tritium is unknown and probably highly nonuniform, the likelihood of an individual well detecting measurable concentrations is unknown. By 100 years, the leading edge is estimated to have moved to about $3 \mathrm{~km}$ downgradient and the center of mass to about $830 \mathrm{~m}$ downgradient.

The outer limits of most of the tritium mass and the location of the tritium center of mass over time are shown in Figure 13, although it should be noted that the log-log scale of this plot de-emphasizes the more rapid increase in longitudinal spreading of the solute mass with respect to transverse spreading. Due to increasing longitudinal spreading with time, the leading edge covers the 11.3-km distance to the Pecos River in approximately 350 years. Of course, most of the tritium mass will be lost to radioactive decay during that time period. The difference between the 350 -year leading edge arrival time indicated by the spatial moments and the 11-year peak of the travel-time pdf results from three factors. First, the spatial moment analysis does not account for uncertainty in parameter estimates so the moments of displacement are underestimated. However, parameter uncertainty is minimal compared to the very high spatial variability incorporated in this analysis so the magnitude of the underestimates should be very small. Secondly, the travel-time analysis 


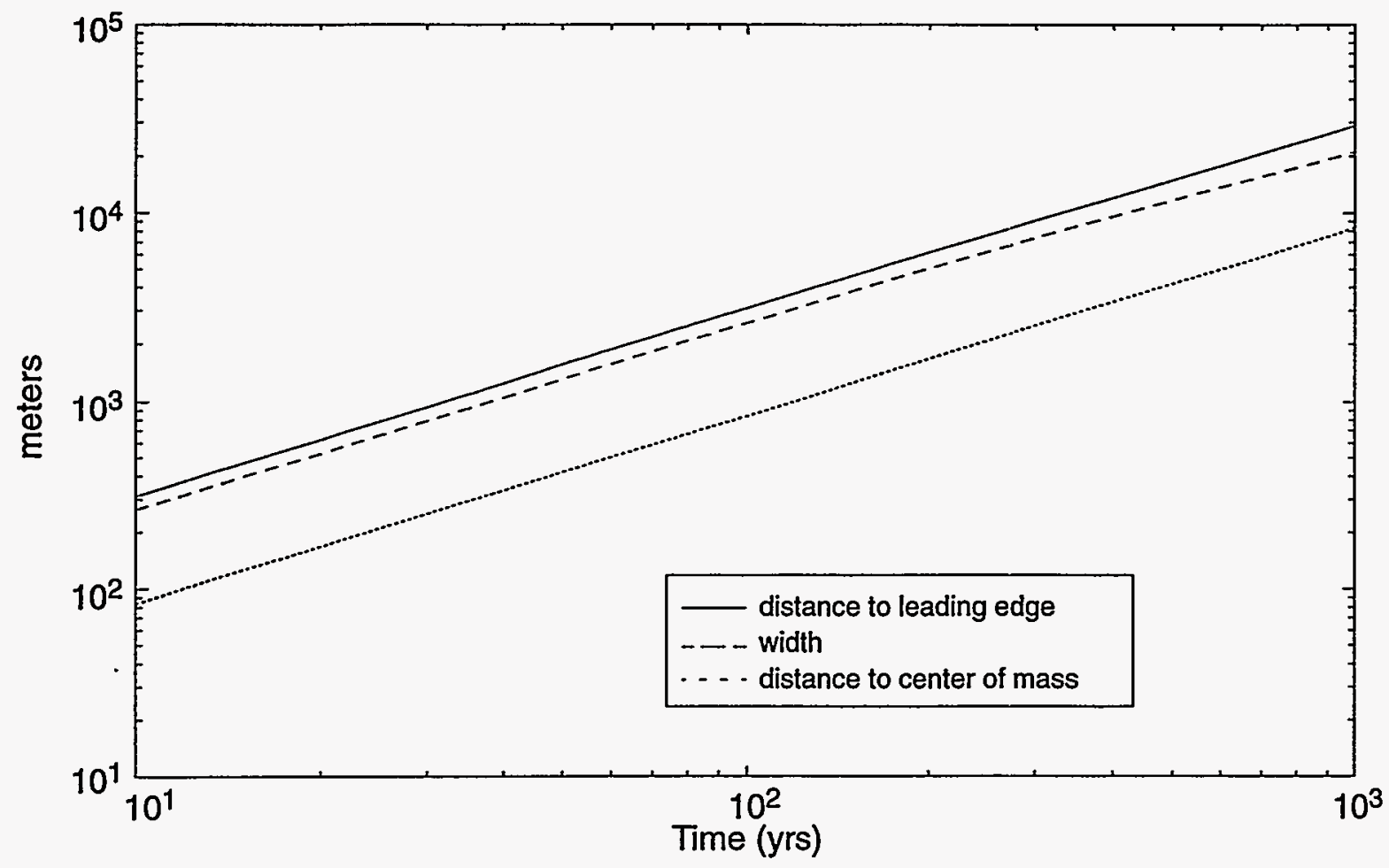

Figure 13. Tritium displacement verses time represented by the location of the leading edge, width, and center of mass. The distances to the leading edge and center of mass are measured from the source.

accounts for radioactive decay of the tritium mass and this decay removed the longer times from the travel-time distribution. The 11-year travel-time peak represents the time at the Pecos River when, due to the longer groundwater travel times, tritium decay begins to reduce the tritium mass that reaches the river each year. In contrast, the spatial moment analysis does not account for the effects of radioactive decay during transport because the displacement of mass is not affected by decay. Finally, each method of analysis defines the leading edge in a different way. The analysis of spatial moments focused on the near field so the leading edge was defined as $2 \sigma$ of spreading downgradient from the center of mass, thereby incorporating an area encompassing about 95 percent of the tritium mass. The highly heterogeneous log-normally distributed flow field suggests that the remaining 5 percent of the mass is spread over a very large area. In contrast, the travel-time analysis focused on a long distance $(11.3 \mathrm{~km})$, and very early arrival times, so the leading edge was defined as the peak of the travel-time pdf. As a result, the leading edge corresponded to only a few hundredths of a percent of the source mass passing the control plane. The leading edge defined by the spatial moments is more useful for monitoring purposes. This is because it defines the geographic area where the bulk of the mass resides and therefore where the concentrations of tritium in groundwater are most likely to be detected. 
The sensitivity of the estimates of the spatial moments to the values of the input parameters is useful for understanding the relative importance of the parameters to tritium migration. The results are presented in Figures 14 through 16 as the distances on the coordinate axes of the outer limits of the mass. The downgradient distance represents the distance from the source to the leading edge, as defined by the sum of the distance to the center of mass and $2 \sigma$ of spreading. The width represents $4 \sigma$ of spreading perpendicular to the mean flow direction (i.e., the transverse width of the ellipses shown in Figure 11). The parameter values were the same as those used in the travel-time analysis. Each varied parameter was adjusted through ranges at least as large as the ranges used in the travel-time sensitivity analysis.

The results suggest that tritium displacement is more sensitive to the magnitude of transmissivity, and therefore groundwater flow velocity, than to transmissivity variability and spatial correlation. This indicates that during the 31-year period of transport, the bulk of the tritium has not moved far enough to intercept all the variability in the transmissivity field or be influenced by spatial persistence of high values of transmissivity. Note, however, that adjustment of $\lambda$ through the range of about 20 to $300 \mathrm{~m}$ causes the greatest change in spatial moments (Figure 15). This results from the center of mass moving a distance that is several times these values of the correlation scale over the 31-year period of transport and thus intercepting a significant portion of the variability in the flow field. As $\lambda$ is increased beyond about $1000 \mathrm{~m}$, changes in spreading are minimal.

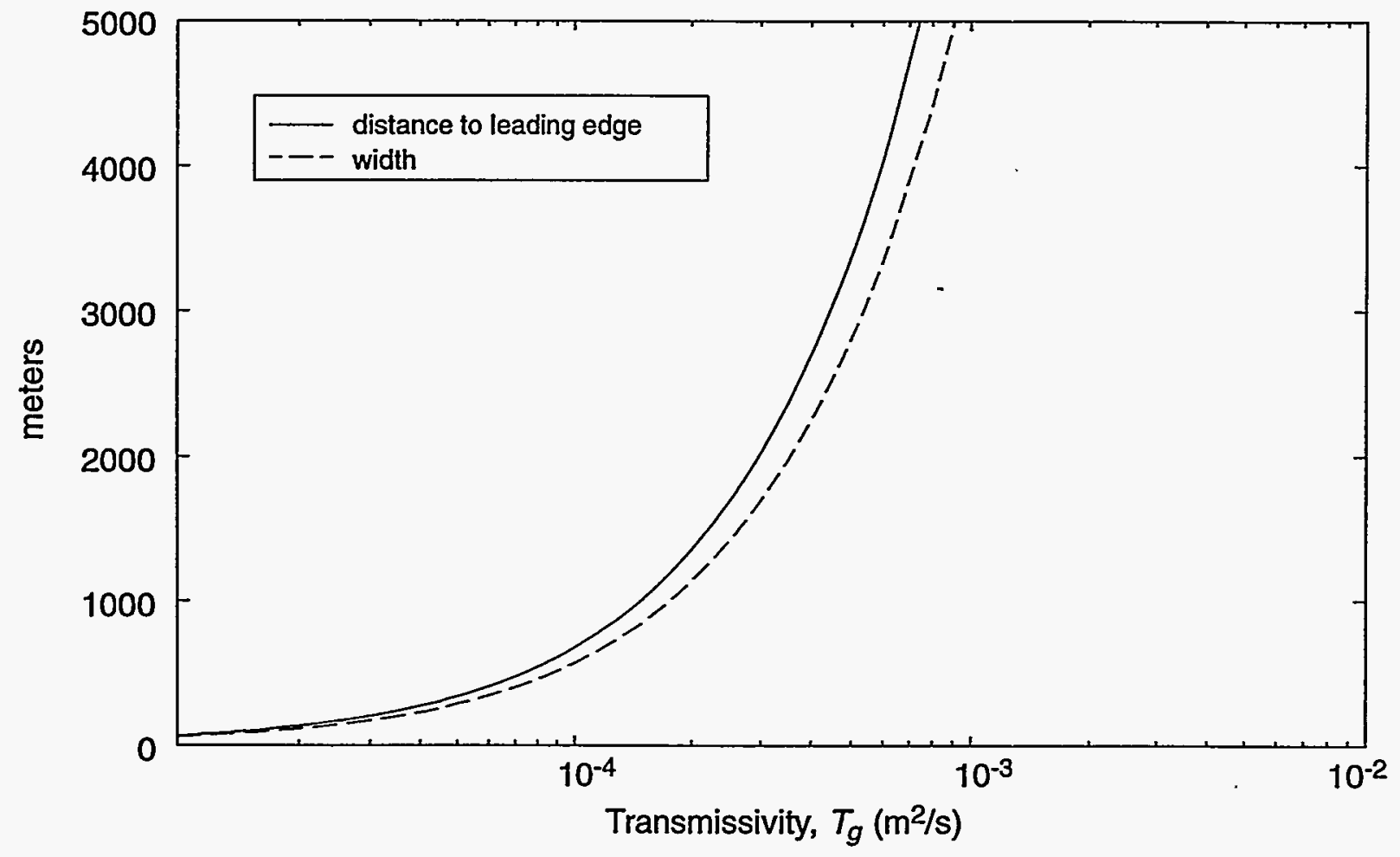

Figure 14. Sensitivity of tritium displacement to transmissivity, $T$, at $t=31$ years. 


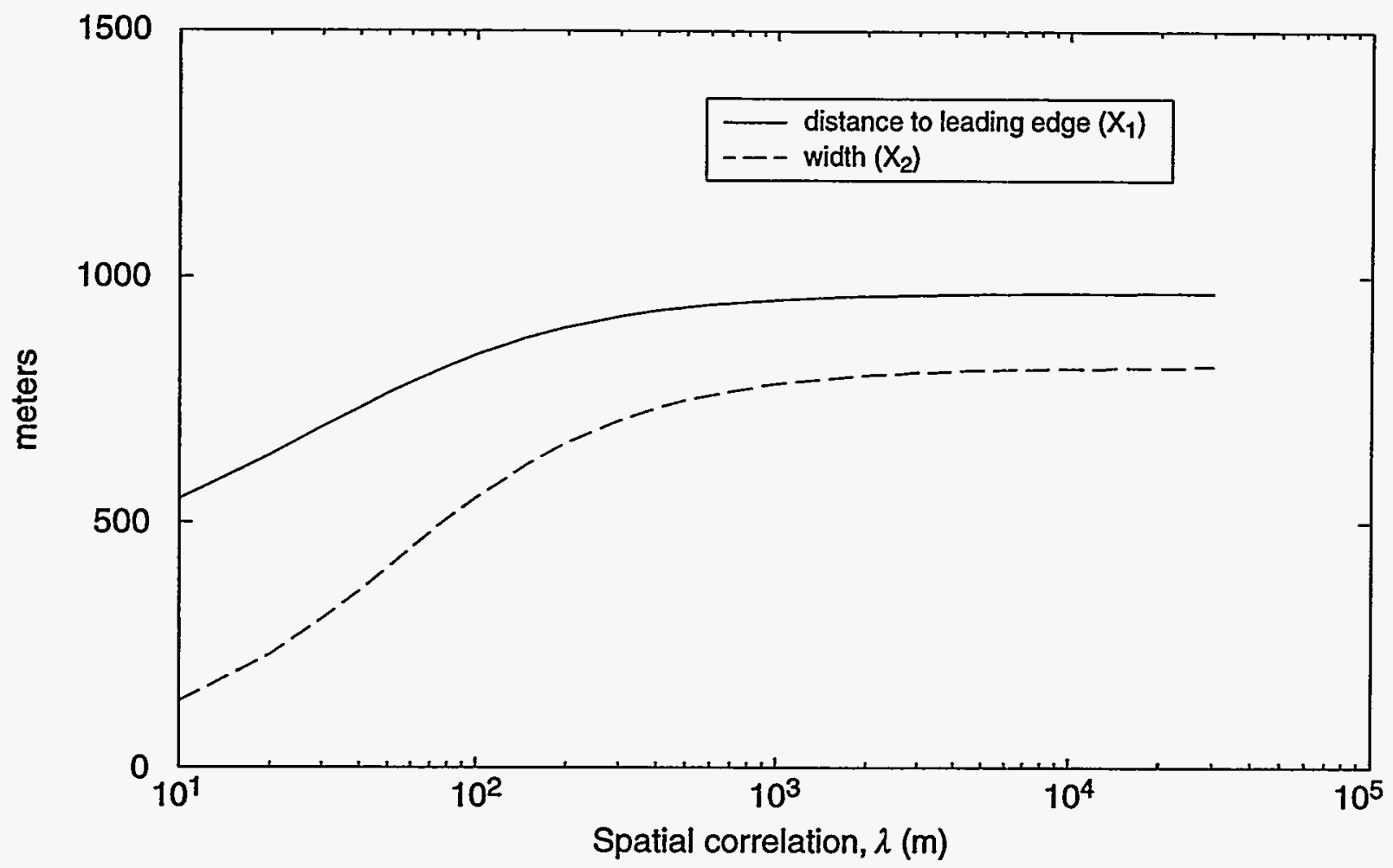

Figure 15. Sensitivity of tritium displacement to spatial correlation scale, $\lambda$, at $t=31$ years.

\section{CONCLUSIONS AND RECOMMENDATIONS -}

The objective of this scoping study was to investigate groundwater transport of tritium away from radioactive tracer tests conducted in 1963 in the vicinity of Project Gnome. The scoping calculations provide an assessment of the factors important to groundwater transport at the Gnome site. Both the travel-time method and the spatial moments method utilized here incorporate heterogeneity in the Culebra dolomite aquifer by treating transmissivity as a spatially correlated random field. The travel-time approach also incorporates uncertainty in parameter estimation. Because little hydrogeologic data were available downgradient from Gnome, most of the data used in the analysis originated from investigations at the WIPP site, which is located approximately $9 \mathrm{~km}$ to the northeast and hydraulically upgradient.

The results indicate that significant spreading of tritium will occur as a result of the combination of relatively high transmissivity, high spatial variability, and high spatial correlation of transmissivity of the Culebra dolomite. In particular, longitudinal spreading causes a very small fraction of tritium mass to arrive at the Pecos River within 30 years of the tracer test. However, dilution and transverse dispersion will act to distribute the tritium mass over a large volume of groundwater, thereby reducing groundwater concentrations. Realistic estimates of these 


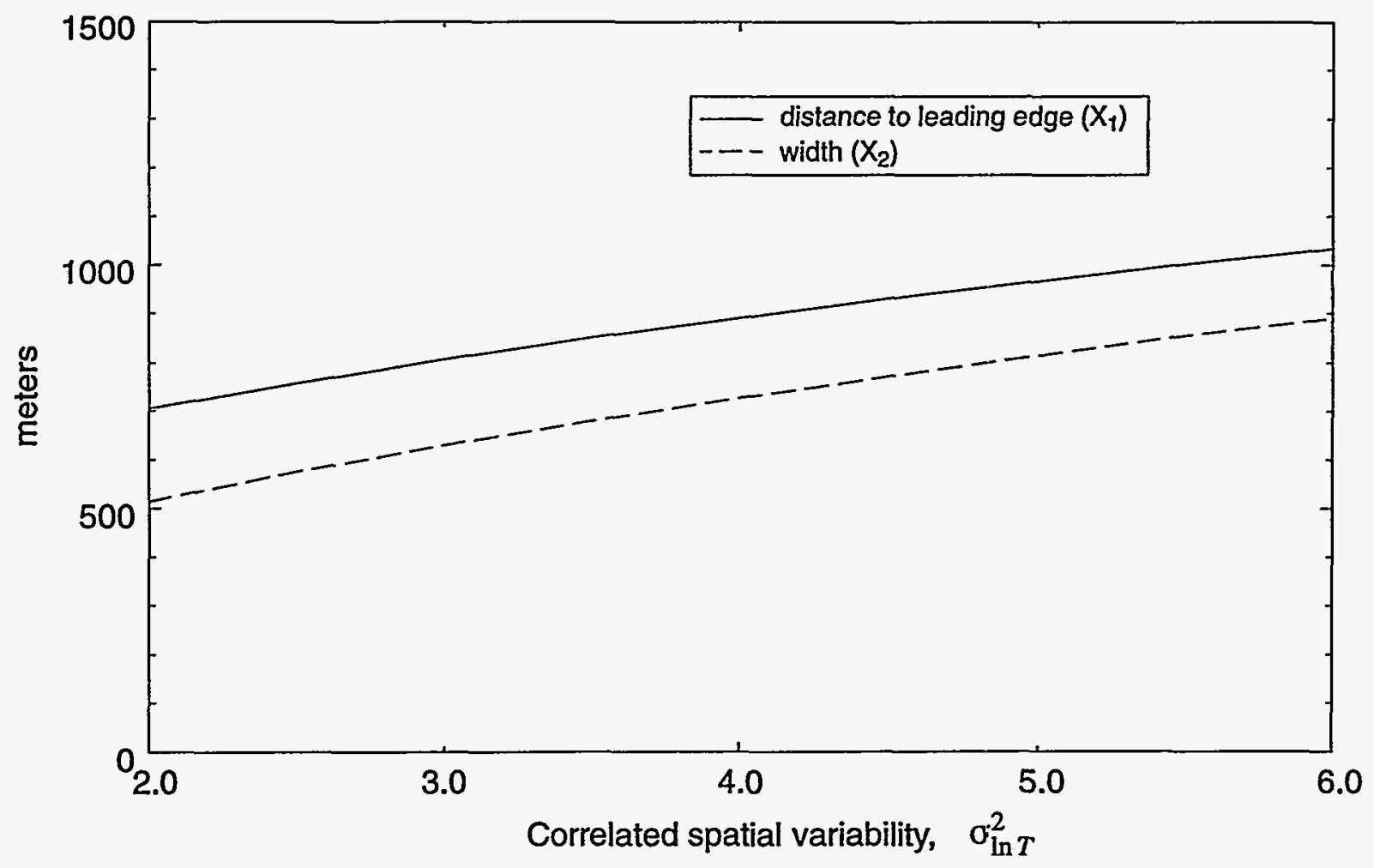

Figure 16. Sensitivity of tritium displacement to correlated spatial variability, $\sigma^{2} \ln T$, at $\mathrm{t}=31$ years.

concentrations must incorporate dilution and dispersion but these processes are very difficult to characterize, particularly at the leading edge, and thus were not attempted in these scoping calculations. Despite the distant transport of a very small fraction of tritium mass, the bulk of the tritium remains near the source. At the present time ( 31 years after the tracer test), the center of mass is estimated to have moved approximately $260 \mathrm{~m}$ downgradient of the test location and about 95 percent of the mass is estimated to have remained within $1 \mathrm{~km}$ downgradient.

Verification of the mechanisms contributing to tritium migration and spreading will require the collection of additional field data, particularly near the source. Drilling efforts downgradient of the tracer test site would supplement the existing database and, more importantly, provide critical information on the hydraulic and transport characteristics in the area where transport occurs. For example, the sensitivity of these calculations to the mean, total variability, and spatial correlation of transmissivity suggest that these parameters should be better defined for the downgradient area of transport. If possible, the transmissivity nugget effect should be addressed and characterized. Monitoring wells sited within $1 \mathrm{~km}$ downgradient of the site should assist in defining the near-field geometry of the tritium plume, while wells sited approximately $1 \mathrm{~km}$ or more downgradient should provide information near the leading edge of the plume. Investigation of radionuclide distribution 
between the water, rock matrix, and fractures downgradient of the source will provide invaluable information on the transport and fate of radionuclides in fractured rock under natural hydraulic gradients.

To improve the description of radionuclide migration at the Gnome site, groundwater transport of sorbing radionuclides should also be investigated. Groundwater dilution of the radionuclide mass should be investigated and included during the site investigation. Characterization of dilution effects would allow realistic estimates of radionuclide concentrations in groundwater.

\section{REFERENCES}

Andricevic, R., J.I. Daniels and R.L. Jacobson, 1994. Radionuclide migration using travel time transport approach and its application in risk analysis. Water Resour. Res., in press.

Beetem, W.A. and C.G. Angelo, 1964. Tracer study at Project Gnome site, near Carlsbad, New Mexico: Background information. Technical Letter: Carlsbad Hydrology-2, U.S. Geological Survey.

Cauffman, T.L., A.M. LaVenue and J.P. McCord, 1990. Ground-water flow modeling of the Culebra Dolomite. Volume II: Data base. SAND89-7068/2, prepared for Sandia National Laboratories by INTERA Technologies, Inc.

Chapman, J.B. and S. Hokett, 1991. Evaluation of groundwater monitoring at offsite nuclear test areas. Publication No. 45085, Water Resources Center, Desert Research Institute.

Cooper, J.B. and V.M. Glanzman, 1971. Geohydrology of Project Gnome Site, Eddy County, New Mexico. Professional Paper 712-A, U.S. Geological Survey.

Dagan, G., 1982. Stochastic modeling of groundwater flow by unconditional and conditional probabilities. 2: The solute transport. Water Resour. Res. 18, 835-348.

Dagan, G., 1984. Solute transport in heterogeneous porous formations. J. Fluid Mech., 145, 151-177.

Dagan, G., 1987. Theory of solute transport by groundwater. Ann. Rev. Fluid Mech., 19, 183-215.

Dagan, G., 1989. Flow and Transport in Porous Formations, Springer-Verlag, Berlin.

Dagan, G. and V. Nguyen, 1989. A comparison of travel time and concentration approaches to modeling transport by groundwater. J. Contam. Hydrol., 4, 79-91.

Freeze, R.A. and J.A. Cherry, 1979. Groundwater. Prentice-Hall, Englewood Cliffs, New Jersey.

Gard, L.M., Jr., 1968. Geologic Studies: Project Gnome, Eddy, County, New Mexico. Professional Paper 589, U.S. Geological Survey.

Grove, D.B. and W.A. Beetem, 1971. Porosity and dispersion calculations for a fractured carbonate aquifer using the two well tracer method. Water Resour. Res., 7(1), 128-134. 
Haug, A., V.A. Kelley, A.M. LaVenue and J.F. Pickens, 1987. Modeling of ground-water flow in the Culebra Dolomite at the Waste Isolation Pilot Plant (WIPP) site: Interim report. SAND86-7167, prepared for Sandia National Laboratories by INTERA Technologies, Inc.

Hoeksema, R.J. and P.K. Kitinidis, 1985. Analysis of the spatial structure of properties of selected aquifers. Water Resour. Res., 21(4), 563-572

Kelley, V.A. and G.J. Saulnier, Jr., 1990. Core analysis for selected samples from the Culebra Dolomite at the Waste Isolation Pilot Plant site. SAND90-7011, prepared for Sandia National Laboratories by INTERA Technologies, Inc.

Kinzelbach, W., 1988. The random walk method in pollutant transport simulations. Groundwater Flow and Quality Modeling, E. Custodio, A. Gurgui, and J.P.L. Ferreira (eds.). D. Reidel, Hingham, Mass.

Lappin, A.R., 1988. Summary of site-characterization studies conducted from 1983 through 1987 at the Waste Isolation Pilot Plant (WIPP) site, southeastern New Mexico. SAND88-0157, Sandia National Laboratories.

LaVenue, A.M., T.L. Cauffman and J.F. Pickens, 1990. Ground-water flow modeling in the Culebra Dolomite. Volume I: Model calibration. SAND89-7068/1, prepared for Sandia National Laboratories by INTERA Technologies, Inc.

Lowenstein, T.K., 1987. Post burial alteration of the Permian Rustler Formation evaporites, WIPP site, New Mexico: textural, stratigraphic and chemical evidence. New Mexico Environ. Eval. Group, EEG-36.

Reeves, M., V.A. Kelley and J.F. Pickens, 1987. Regional double-porosity solute transport in the Culebra dolomite: An analysis of parameter sensitivity and importance at the Waste isolation Pilot Plant (WIPP) site. SAND87-7105, prepared for Sandia National Laboratories by INTERA Technologies, Inc.

Shapiro, A.M. and V. Cvetkovic, 1988. Stochastic analysis of solute arrival time in heterogeneous porous media. Water Resour. Res., 24(10), 1711-1718.

Snyder, R.P., 1985. Dissolution of halite and gypsum, and hydration of anhydrite to gypsum, Rustler Formation, in the vicinity of the Waste Isolation Pilot Plant, southeastern New Mexico. Open-File Report 85-229, U.S. Geological Survey.

Tompson, A.F.B., 1993. Numerical simulation of chemical migration in physically and chemically heterogeneous porous media. Water Resour. Res., 29(11), 3709-3726. 
APPENDIX A

DESCRIPTION OF TRAVEL-TIME AND SPATIAL-MOIMENTS METHODS 
The travel-time methodology applied here follows the Lagrangian concept of particle displacement in heterogeneous porous media developed by Dagan $(1982,1984,1987)$, Dagan and Nguyen (1989), and Shapiro and Cvetkovic (1988) where the solute is represented as a collection of particles transported by groundwater under advection, dispersion, and other chemical and physical processes. The particle movement can be described by its arrival time at a plane perpendicular to the direction of mean flow. This arrival time $t$ is defined at a distance $L$ from the injection point as (Shapiro and Cvetkovic, 1988)

$$
t(L)=\int_{0}^{L} \frac{d x_{1}}{V\left(x_{1}\right)}
$$

where $V\left(x_{1}\right)$ is the velocity in the mean flow direction. This study assumes a steady-state velocity field $V(x)$, in the space coordinate $x$, which satisfies both the Darcy and the continuity equations. $V(x)$ is the sum of the ensemble average vector of the velocity field $U$ and a random fluctuation $v(x)$ that depends only on the distance between the points. The combination of the spatial variability of aquifer properties and the uncertainty in the estimates of these properties means that the arrival time at $L, t(L)$, is a random function described by the probability density function (pdf) $p[t ; L]$.

The mean groundwater velocity, also referred to as the average linear velocity, is generally not directly measured but rather estimated from both the field data and the modified Darcy equation, which in two-dimensional form is

$$
U=\frac{T_{g} J}{b n}
$$

where $T_{g}$ is the geometric mean of transmissivity, $J$ is the mean hydraulic gradient, $n$ is the mean effective porosity, and $b$ is the mean aquifer thickness.

Because transmissivity is generally assumed to be log-normally distributed in bedrock aquifers (Hoeksema and Kitinidis, 1985; Dagan, 1989), $\ln T(x)$ is distributed normally with mean $\mu_{\ln T}$, variance $\sigma^{2} \ln T$, and a prescribed correlation structure. If the negative exponential function is assumed for the correlation structure of $T(x)$ (Hoeksema and Kitinidis, 1985), the covariance function of an isotropic $T$ field is described by

$$
R_{\ln T}(r)=C_{0} \delta(h)+\sigma_{\ln T}^{2} \exp \left[-\frac{h}{\lambda}\right]
$$

where $C_{0}>0$ is the nugget variance, $\delta(h)$ is the Kronecker delta that is 1 if $\mathrm{h}=0$ and 0 for all other cases, $h$ is the distance between data points, and $\lambda$ is the correlation length of $\ln T(x)$. Thus, the random $T$ field is statistically characterized by three parameters: $\mu_{\ln T}, \sigma^{2} \ln T$, and $\lambda$. The nugget 
variance represents small-scale variability (scale shorter than the sampling interval) as well as measurement uncertainty and is distinct from the variability attributed to spatial separation.

If all the parameters on the right-hand side of (2) are log-normally distributed, then so is $U$, such that the first two moments of the mean velocity estimate are

$$
\begin{array}{r}
\mu_{\ln U}=\mu_{\ln T}+\mu_{\ln J}-\mu_{\ln b}-\mu_{\ln n} \\
\sigma^{2} \ln U=\sigma^{2} \ln T+\sigma^{2} \ln J+\sigma^{2} \ln b+\sigma^{2} \ln n
\end{array}
$$

Correlations between terms in equation (A.5) are neglected because little data are available to justify choice of values and because these terms are small compared to the overall uncertainty (Andricevic et al., 1994). The magnitude of the uncertainty in the estimate of $U, \mathrm{o}^{2} \ln U$, therefore, depends on the estimation error of $T, J, b$, and $n$. The number of measurements used to estimate some of the parameters, particularly $\mu_{\ln T}$, will affect the variance of estimation (i.e. $\sigma^{2} \ln T$ ) through the estimation technique directly (e.g., maximum likelihood, non-linear regression) or by scaling the population variance with the number of measurements $N$ if data are independent, or if the data are spatially correlated, by

$$
\operatorname{Var}\left(\bar{X}_{\ln T}\right)=\frac{\sigma_{\ln T}^{2}}{N}[1+\bar{\varrho}(N-1)]
$$

where $\bar{\varrho}$ is the averaged spatial correlation between the data points given by

$$
\bar{\varrho}=\exp \left[-\frac{\bar{h}}{\lambda}\right]
$$

In the case of pure advection, the travel time to the distance $L$ from the source is given by $t(L)$ $=L / U$, which can be described by the travel-time pdf of the log-normal form

$$
p[t ; L]=\left(\sqrt{2 \pi} \sigma_{\ln t} t\right)^{-1} \exp \left[-\frac{\left(\ln t-\mu_{\ln t}\right)^{2}}{2 \sigma_{\ln t}^{2}}\right]
$$

where $\mu_{\ln t}=\ln L-\mu_{\ln U}$ and $\sigma^{2}{ }_{\ln t}=\sigma^{2} \ln U$. This travel-time distribution is essentially the ensemble mean solution (because only the mean velocity is used as the transport mechanism) together with the uncertainty in the mean velocity estimate. By considering the uncertainty in the mean velocity (estimated through equation (A.5)) the shape of the travel-time pdf is a direct result of the variability in the estimated mean velocity $U$, but does not incorporate spatial variability in the flow field.

To obtain a more realistic simulation of groundwater transport, macrodispersion of the solute that results from aquifer heterogeneity must be included in the calculations. This can be 
accomplished by utilizing the travel-time pdf given in (8) but with the first two moments now calculated accounting for the spatially variable velocity field. Shapiro and Cvetkovic (1988) obtained, for the isotropic case, the mean arrival time $\langle t(L)\rangle=L / U$ and the arrival time variance for large times, $L \rightarrow \infty$, as

$$
\sigma_{t}^{2}=2 L \lambda \sigma_{\ln T}^{2}\left[\frac{1}{U}\right]^{2}
$$

This expression, when converted into the log space and used in (A.8), provides the travel-time pdf for the spatially variable velocity field, which is described by the mean velocity $U$, the variance of $\log$-transmissivity $\sigma^{2} \ln T$, and the transmissivity integral scale, $\lambda$.

The travel-time model can be modified to account for radioactive decay of tritium during groundwater transport. Radioactive decay is a first-order reaction and can be incorporated in the travel-time pdf as

$$
\tilde{p}[t ; L]=\exp \left(-\frac{\ln 2}{\alpha} t\right) p[t ; L]
$$

where $\alpha$ is the radionuclide half-life, and $p[t ; L]$ is the travel-time pdf for the solute given in (A.8) which, when incorporating (A.9), accounts for advection and hydrodynamic dispersion. The function $p[t ; L]$ is the "defective" travel-time pdf in that it does not conserve mass (due to radioactive decay) and therefore the total probability is less than one.

The travel-time analysis described above is important because it can be used to describe solute mass flux as a function of time at a given distance where exposure or access to groundwater is possible. This approach is particularly applicable to problems that involve risk assessment at the accessible environment (Andricevic et al., 1994). On the other hand, analysis of tritium spatial moments, which describe displacement of the tritium in space, is most useful for studying the behavior of the tritium mass at fixed times. Ensemble averages of these spatial moments can be made by averaging many stochastic realizations of the plume created numerically by the particle tracking random walk (PTRW) method (Kinzelbach, 1988), but the computer- and data-intensive nature of that method was not considered justified for this study. Dagan (1989) presented an analytical solution for the first two moments of displacement of a nonreactive solute in a heterogeneous aquifer from an instantaneous point source. Like the travel-time approach described above, Dagan's solution represents the spatially variable transmissivity field as a two-dimensional random field that can be statistically characterized by $\mu_{\ln T}, \sigma^{2} \ln T$, and $\lambda$, with a $\log$-normal distribution of $T$. 
The first moment of displacement describes the mean location (center of mass) of the tritium and is simply a linear function of time (Dagan, 1989). It is calculated from

$$
X_{L}=U t
$$

The second moments describe the spreading of mass about the mean location and can be determined for two-dimensional flow from (Dagan, 1989):

$$
\begin{gathered}
\frac{X_{1}(\omega)}{\lambda^{2}}=\sigma_{\ln T}^{2}\left[2 \omega-3 \ln \omega+\frac{3}{2}-3 E+3 E i(-\omega)+3 e^{-\omega}\left(1+\frac{1}{\omega}\right) \frac{1}{\omega}-\frac{3}{\omega^{2}}\right] \\
\frac{X_{2}(\omega)}{\lambda^{2}}=\sigma_{\ln T}^{2}\left[\ln \omega-\frac{3}{2}+E-E i(-\omega)-3 e^{-\omega}\left(1+\frac{1}{\omega}\right) \frac{1}{\omega}+\frac{3}{\omega^{2}}\right]
\end{gathered}
$$

where $E=0.577 \ldots$ is Euler's number, $E i$ is the exponential integral function, the subindexes indicate the orientation of the second moment ( 1 is the longitudinal axis, 2 is the transverse axis), and $\omega$ is the dimensionless variable

$$
\omega=\frac{U t}{\lambda}
$$

where $U$ is the mean linear groundwater velocity, $t$ is the time period over which transport is occurring, and $\lambda$ is the correlation length of $\ln T$.

Note that parameter estimation uncertainty is not incorporated in the calculation of the spatial moments; therefore, tritium spreading will be slightly underestimated. 


\section{APPENDIX B \\ WELL DATA FOR THE VICINITY OF GNOME (Compiled from Cauffman et al., 1990)}




\begin{tabular}{|c|c|c|c|c|c|c|c|}
\hline \multirow{2}{*}{$\begin{array}{l}\text { Well No. } \\
\text { on } \\
\text { Fig. } 4\end{array}$} & \multirow{2}{*}{$\begin{array}{l}\text { Well } \\
\text { ID }\end{array}$} & \multicolumn{2}{|c|}{ UTM Coordinates } & \multirow{2}{*}{$\begin{array}{c}\text { Culebra } \\
\text { Transmissivity } \\
\left(\mathrm{m}^{2} / \mathrm{s}\right)\end{array}$} & \multirow{2}{*}{$\begin{array}{l}\text { Type } \\
\text { of } \\
\text { Test }\end{array}$} & \multirow{2}{*}{$\begin{array}{l}\text { Avg. of more } \\
\text { than } 1 \text { test } \\
\text { (yes or no) }\end{array}$} & \multirow{2}{*}{$\begin{array}{c}\text { Culebra } \\
\text { Thickness } \\
\text { (m) }\end{array}$} \\
\hline & & East (m) & North (m) & & & & \\
\hline 1 & $\mathrm{H}-1$ & 613423 & 3581684 & $9.36 e-07$ & $S$ & no & 7.01 \\
\hline 2 & $\mathrm{H}-2$ & 612660 & 3581652 & $6.30 \mathrm{e}-07$ & S,P,I,D & yes & 6.10 \\
\hline 3 & $\mathrm{H}-3$ & 613714 & 3580892 & $2.46 e-06$ & $\mathrm{P}, \mathrm{I}$ & yes & 7.22 \\
\hline 4 & $\mathrm{H}-4$ & 612398 & 3578484 & $1.01 \mathrm{e}-06$ & P,I & yes & 7.72 \\
\hline 5 & $\mathrm{H}-5$ & 616888 & 3584793 & $9.74 e-08$ & S,P,I & yes & 7.21 \\
\hline 6 & $\mathrm{H}-6$ & 610595 & 3584991 & $3.55 e-05$ & $P, I$ & yes & 7.01 \\
\hline 7 & $\mathrm{H}-7$ & 608109 & 3574644 & $1.54 \mathrm{e}-03$ & I & yes & 11.3 \\
\hline 8 & $\mathrm{H}-8$ & 608668 & 3563553 & $8.82 \mathrm{e}-06$ & $\mathrm{P}$ & no & 7.92 \\
\hline 9 & $\mathrm{H}-9$ & 613974 & 3568252 & $1.25 \mathrm{e}-04$ & I & yes & 9.14 \\
\hline 10 & $\mathrm{H}-10$ & 622967 & 3572458 & $7.53 e-08$ & $S$ & no & 9.45 \\
\hline 11 & $\mathrm{H}-11$ & 615341 & 3579124 & $3.12 \mathrm{e}-05$ & $\mathrm{~S}, \mathrm{P}, \mathrm{I}$ & yes & 7.47 \\
\hline 12 & $\mathrm{H}-12$ & 617023 & 3575452 & $1.94 \mathrm{e}-07$ & $S$ & no & 8.23 \\
\hline 13 & $\mathrm{H}-14$ & 612341 & 3580354 & $3.28 \mathrm{e}-07$ & S,D & yes & 8.23 \\
\hline 14 & $\mathrm{H}-15$ & 615315 & 3581859 & $1.32 e-07$ & S,D & yes & 6.71 \\
\hline 15 & $\mathrm{H}-16$ & 613369 & 3582212 & $7.68 \mathrm{e}-07$ & S,I,D & yes & 6.68 \\
\hline 16 & $\mathrm{H}-17$ & 615718 & 3577513 & $2.31 \mathrm{e}-07$ & S,D & yes & 7.80 \\
\hline 17 & $\mathrm{H}-18$ & 612264 & 3583166 & $1.67 e-06$ & $\mathrm{~S}, \mathrm{P}, \mathrm{D}$ & yes & 7.37 \\
\hline 18 & DOE-1 & 615203 & 3580333 & $1.18 e-05$ & $\mathbf{P}$ & no & 7.01 \\
\hline 19 & DOE-2 & 613683 & 3585294 & $9.57 e-05$ & $\mathrm{P}$ & no & 6.71 \\
\hline 20 & $\mathrm{P}-14$ & 609084 & 3581976 & $2.77 e-04$ & $\mathbf{P}$ & yes & 6.71 \\
\hline 21 & P-15 & 610624 & 3578747 & $9.22 \mathrm{e}-08$ & $S, D$ & yes & 6.71 \\
\hline 22 & $\mathrm{P}-17$ & 613926 & 3577466 & $1.08 \mathrm{e}-06$ & $S$ & yes & 7.62 \\
\hline 23 & P-18 & 618367 & 3580350 & $7.53 e-11$ & $S$ & no & 8.53 \\
\hline 24 & WIPP-12 & 613710 & 3583524 & $1.08 \mathrm{e}-07$ & $S$ & no & 7.62 \\
\hline 25 & WIPP-13 & 612644 & 3584247 & $7.42 e-05$ & $P$ & no & 7.01 \\
\hline 26 & WIPP-18 & 613735 & 3583179 & $3.23 e-07$ & $S$ & no & 6.40 \\
\hline 27 & WIPP-19 & 613739 & 3582782 & $6.45 \mathrm{e}-07$ & $S$ & no & 7.01 \\
\hline 28 & WIPP-21 & 613743 & 3582319 & $2.69 \mathrm{e}-07$ & $S$ & no & 7.32 \\
\hline 29 & WIPP-22 & 613739 & 3582653 & $3.98 e-07$ & S & no & 6.71 \\
\hline 30 & WIPP-25 & 606385 & 3584028 & $2.88 \mathrm{e}-04$ & $P$ & yes & 7.62 \\
\hline 31 & WIPP-26 & 604014 & 3581162 & $1.22 \mathrm{e}-03$ & $\mathrm{P}$ & yes & 7.01 \\
\hline 32 & WIPP-27 & 604426 & 3593079 & $4.27 e-04$ & $\mathrm{P}$ & yes & 7.92 \\
\hline 33 & WIPP-28 & 611266 & 3594680 & $2.07 e-05$ & $\mathrm{P}$ & yes & 7.92 \\
\hline 34 & WIPP-29 & 596981 & 3578694 & $1.08 \mathrm{e}-03$ & $\mathbf{P}$ & no & 9.14 \\
\hline 35 & WIPP-30 & 613721 & 3589701 & $2.50 \mathrm{e}-07$ & $S$ & yes & 6.71 \\
\hline 36 & ERDA-9 & 613696 & 3581958 & $5.05 e-07$ & $S$ & no & 7.01 \\
\hline 37 & CB-1 & 613191 & 3578049 & $3.01 e-07$ & $S$ & no & 7.92 \\
\hline 38 & ENGLE & 614953 & 3567454 & $4.62 e-05$ & $P$ & no & 6.71 \\
\hline 39 & USGS-1 & 606462 & 3569459 & $5.52 e-04$ & $\mathbf{P}$ & yes & 9.75 \\
\hline 40 & D-268 & 608702 & 3578877 & $2.04 \mathrm{e}-06$ & $S$ & no & 7.01 \\
\hline \multirow[t]{3}{*}{41} & AEC-7 & 621126 & 3589381 & $2.80 \mathrm{e}-07$ & $S$ & no & 7.92 \\
\hline & \multirow[t]{2}{*}{ Abbreviations: } & \multicolumn{3}{|c|}{$\begin{array}{l}S=\text { Slug test } \\
P=\text { Pumping Test (Single Well) } \\
I=\text { Interference Test }\end{array}$} & & & \\
\hline & & $\mathrm{D}=\mathrm{D}$ & 11 Stem Test & & & & \\
\hline
\end{tabular}


APPENDIX C

VARIOGRAMS OF TRANSMISSIVITY IN THE CULEBBRA DOLOMITE 
Theoretical variogram model:

Type: exponential, nugget: 0.0 , sill: 16.5 , range: $12,000 \mathrm{~m}$

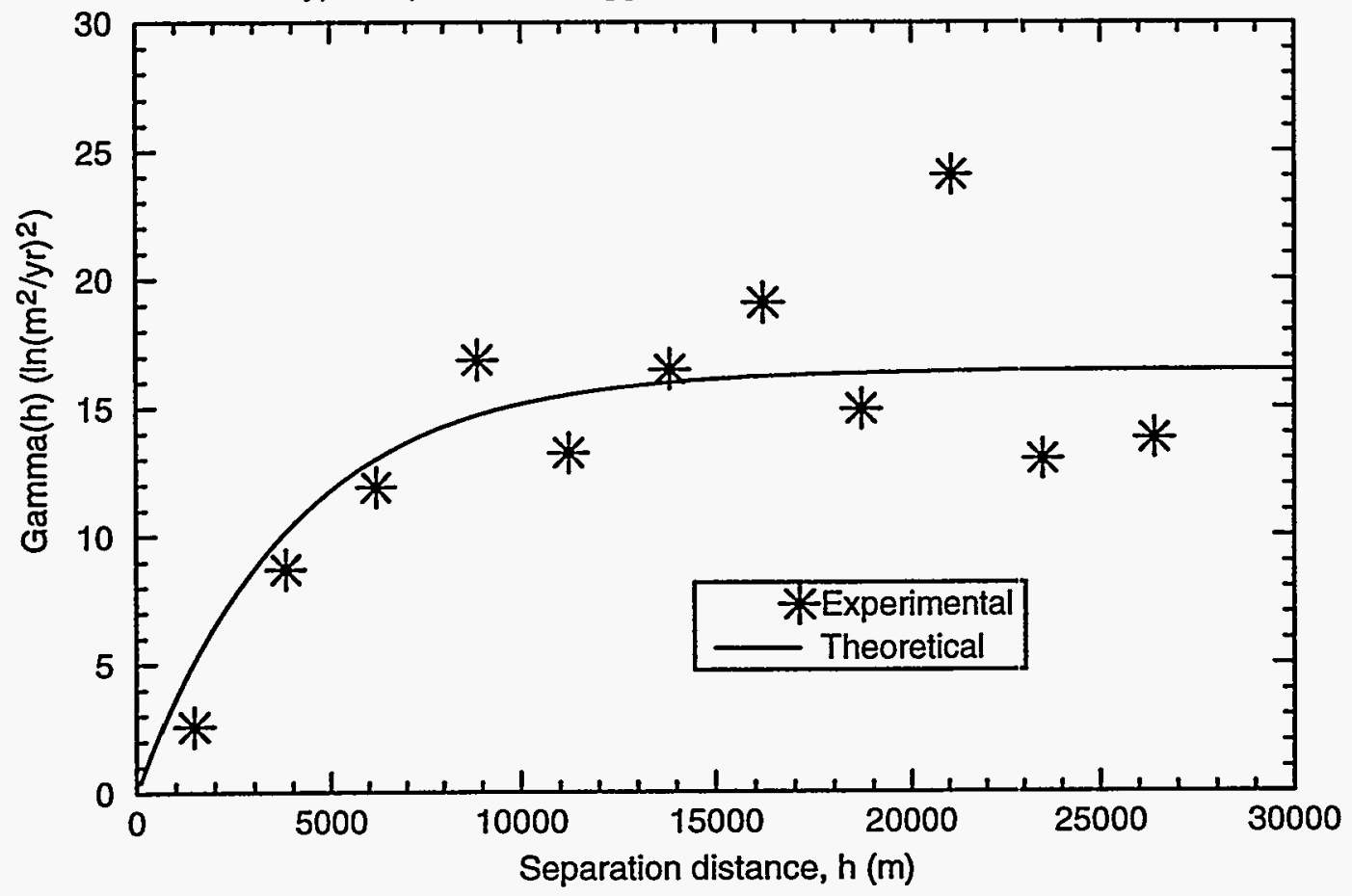

Figure C1. Experimental and theoretical variograms for Dataset 1 (all data points).

Theoretical variogram model:

Type: exponential, nugget: 0.0 , sill: 5.5 , range: $6000 \mathrm{~m}$

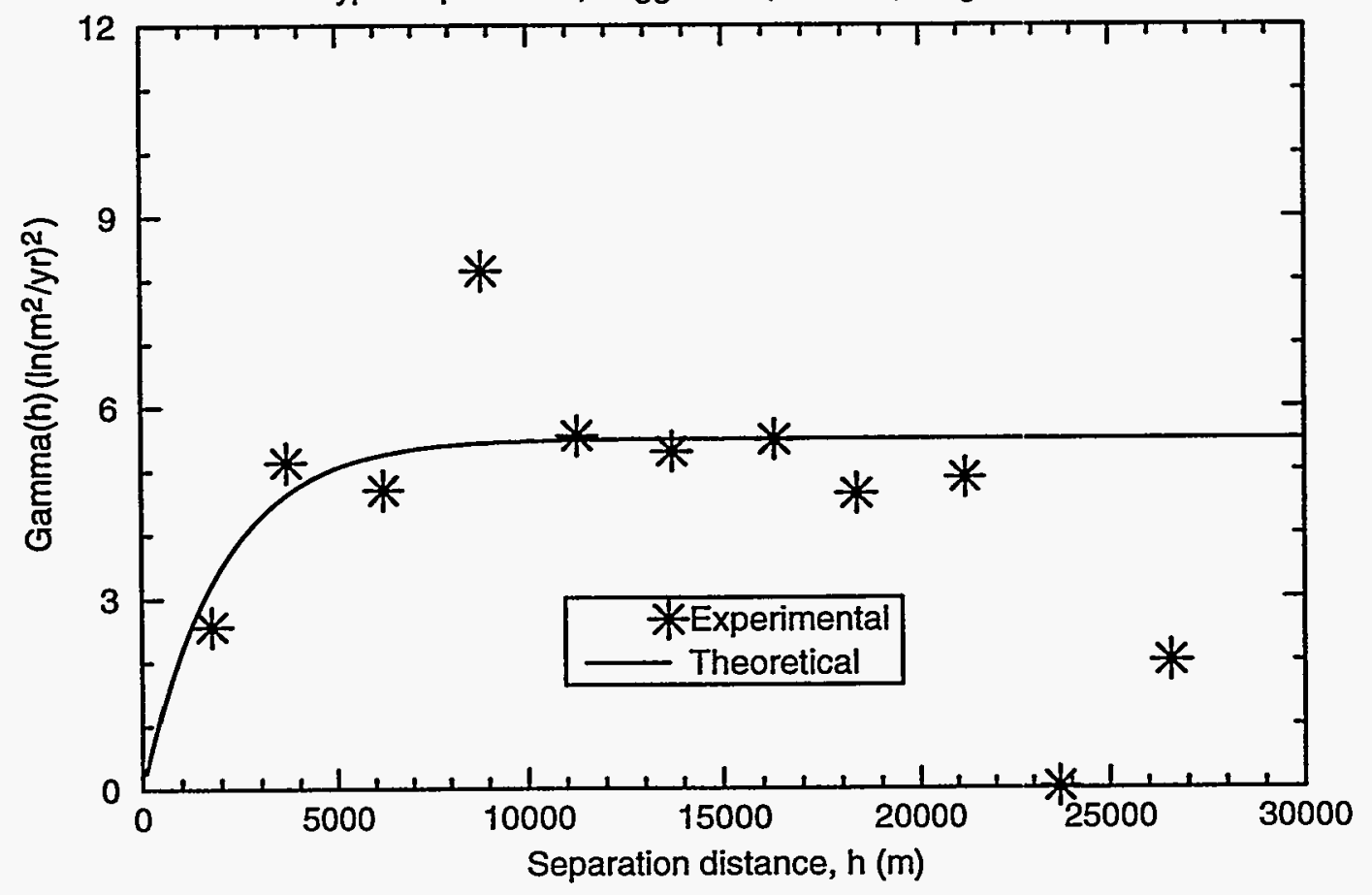

Figure C2. Experimental and theoretical variograms for Dataset 2 (T values greater than $\left.10^{-6} \mathrm{~m}^{2} / \mathrm{s}\right)$. 
Theoretical variogram model:

Type: exponential, nugget: 0.0 , sill: 5.0 , range: $6000 \mathrm{~m}$

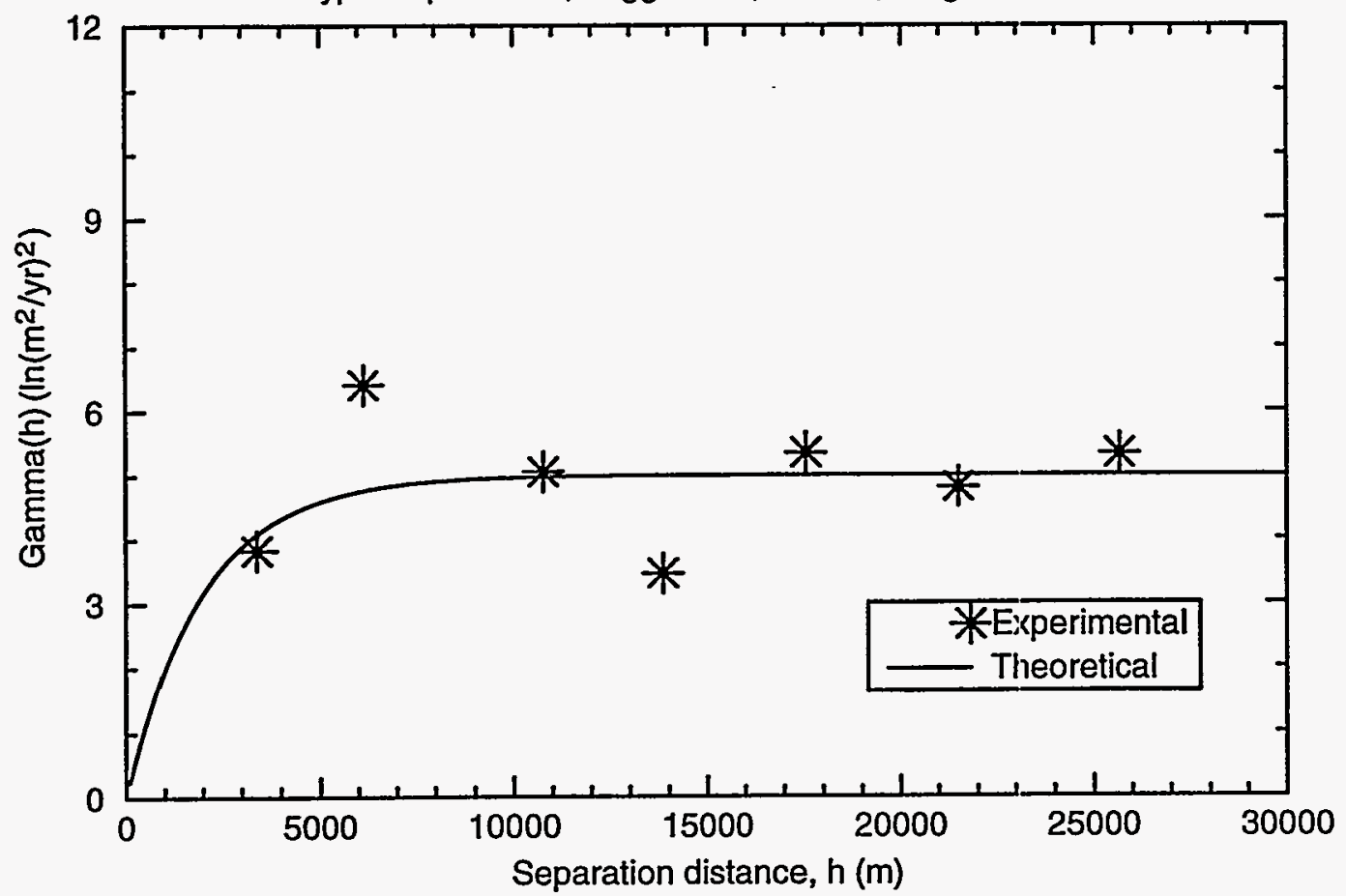

Figure C3. Experimental and theoretical variograms for Dataset 3 (region of halite dissolution). 


\section{DISTRIBUTION}

\section{Desert Research Institute}

Roger Jacobson

Desert Research Institute

Water Resources Center

P.O. Box 19040

Las Vegas, NV 89132-0040

Marjory Jones

Desert Research Institute

Water Resources Center

P.O. Box 60220

Reno, NV 89506-0220

Jenny Chapman

Desert Research Institute

Water Resources Center

P.O. Box 19040

Las Vegas, NV 89132-0040

\section{International Technology Corp.}

Richard M. Deshler

International Technology Corporation

4330 S. Valley View

Suite 114

Las Vegas, NV 89103-4047

Rick Waddell

Geotrans, c/o IT

4330 Valley View

Suite 112, MS-439

Las Vegas, NV 89103-4047

Joe Yeasted

International Technology Corporation

4330 S. Valley View

Suite 114

Las Vegas, NV 89103-4047

\section{Lawrence Livermore National Laboratory}

Lee Davisson

Nuclear Chemistry Division

Lawrence Livermore National Laboratory

P.O. Box 808

L-237

Livermore, CA 94550
Greg Nimz

Lawrence Livermore National Laboratory

P.O. Box 808

MS L233

Livermore, CA 94550

Los Alamos National Laboratory

Joe Thompson

Los Alamos National Laboratory

INC-11, MS J514

P.O. Box 1663

Los Alamos, NM 87545

\section{Raytheon Services Nevada}

Stuart E. Rawlinson

Raytheon Services Nevada

P.O. Box 95487, M/S 580

Las Vegas, NV 89193-5487

Reynolds Electrical \& Engineering Co.

Martha DeMarre

Chief, Document Research Section

Health Protection Dept.

Reynolds Electrical \& Engineering Co.

P.O. Box 98521

Las Vegas, NV 89193-8521

Brian Dozier

Reynolds Electrical \& Engineering Co.

2501 Wyandotte

Mercury, NV 89102

\section{Sandia National Laboratories}

David Gallegos

Sandia National Laboratories

Department 6331

P.O. Box 58.., M/S 1345

Albuquerque, NM 87185-1345

\section{State of Nevada}

Larry Franks

Nevada State Health Department

Radiological Health Section

620 Belrose Avenue

Las Vegas, NV 89158 


\section{U.S. Department of Defense}

David Bedsun

Defense Nuclear Agency

Field Command

Nevada Operations Office

P.O. Box 208

Mercury, NV 89023-0208

\section{U.S. Department of Energy}

Gylan Allen, Director

Test Operations Division

Nevada Operations Office

U.S. Department of Energy

P.O. Box 98518

Las Vegas, NV 89193-8518

Joanne M. Bradbery, Director

Contracts Division

Nevada Operations Office

U.S. Department of Energy

P.O. Box 98518

Las Vegas, NV 89193-8518

Kevin Cabble

Environmental Restoration Division

Nevada Operations Office

U.S. Department of Energy

P.O. Box 98518

Las Vegas, NV 89193-8518

Doug Duncan

Hydrology Program Manager

Office of Environmental Restoration

and Waste Management

Nevada Operations Office

U.S. Department of Energy

P.O. Box 98518

Las Vegas, NV 89193-8518

Donald Elle, Director

Environmental Protection Division

Nevada Operations Office

U.S. Department of Energy

P.O. Box 98518

Las Vegas, NV 89193-8518
Joseph N. Fiore, Acting Assistant Manager

Office of Environmental Restoration

and Waste Managernent

Nevada Operations Office

U.S. Department of Energy

P.O. Box 98518

Las Vegas, NV 89193-8518

Joseph H. Kitchen

Project Control and Technology

Development Division

Nevada Operations Office

U.S. Department of Energy

P.O. Box 98518

Las Vegas, NV 89193-8518

Steve Lawrence

Environmental Restoration Division

Nevada Operations Office

U.S. Department of Energy

P.O. Box 98518

Las Vegas, NV 89193-8518

John S. Ledbetter

Contracts Division

Nevada Operations Office

U.S. Department of Energy

P.O. Box 98518, MS 505

Las Vegas, NV 89193-8518

Kevin Leary

Environmental Restoration Division

Nevada Operations Office

U.S. Department of Energy

P.O. Box 98518

Las Vegas, NV 89193-8518

Steve Leedom

Test Operations Division

Nevada Operations Office

U.S. Department of Energy

P.O. Box 98518

Las Vegas, NV 89193-8518

Steve Mellington, Director

Environmental Restoration Division

Nevada Operations Office

U.S. Department of Energy

P.O. Box 98518

Las Vegas, NV 89193-8518 
Richard Pearl

Environmental Protection Division

Nevada Operations Office

U.S. Department of Energy

P.O. Box 98518

Las Vegas, NV 89193-8518

David S. Shafer

NV/Albuquerque Laboratories Division

Office of Southwestern Area Programs

U.S. Department of Energy

EM-452, Trevion II Bldg.

1000 Independence Ave., SW

Washington, D.C. 20585

\section{U.S. Environmental Protection Agency}

Deb Shaloud

Environmental Monitoring Systems Laboratory

Office of Radiation Protection

U.S. Environmental Protection Agency

P.O. Box 93478

Las Vegas, NV 89193-3478

\section{U.S. Geological Survey}

Virginia Glanzman

U.S. Geological Survey

Box 2506, MS 913

Denver Federal Center

Denver, CO 80225

Randy Laczniak

U.S. Geological Survey

Water Resources Division

6770 S. Paradise Rd.

Las Vegas, NV 89119

Paul Orkild

U.S. Geological Survey

Box 2506, MS 913

Denver Federal Center

Denver, CO 80225

Doug Trudeau

U.S. Geological Survey

Water Resources Division

6770 S. Paradise Rd.

Las Vegas, NV 89119

\section{LIBRARIES}

Annie Kelley

State Documents Department

Nevada State Library

Capitol Complex

Carson City, NV 89710

Archives

Getchell Library

University of Nevada, Reno

Beverly Carter

MacKay School of Mines Library

University of Nevada, Reno

Document Section, Library

University of Nevada, Las Vegas

4505 Maryland Parkway

Las Vegas, NV 89154

Library (Stead)

Desert Research Institute

P.O. Box 60220

Reno, Nevada 89506-0220

Library

IT Corporation

4330 S. Valley View

Suite 114

Las Vegas, NV 89103

ATTN: Toni Miller

Library

Southern Nevada Science Center

Desert Research Institute

P.O. Box 19040

Las Vegas, NV 89132-0040

Technical Information Resource Center

Nevada Operations Office

U.S. Department of Energy

P.O. Box 98518

Las Vegas, NV 89193-8518

Water Resources Research Archives

University of California

Room 40, North Gate Hall

Berkeley, CA 94720 